\title{
Inhibition of HIF-prolyl-4-hydroxylases prevents mitochondrial impairment and cell death in a model of neuronal oxytosis
}

\author{
S Neitemeier ${ }^{1}$, AM Dolga ${ }^{1}$, B Honrath ${ }^{1}$, SS Karuppagounder ${ }^{2,3}$, I Alim², ${ }^{2,3}$, RR Ratan ${ }^{2,3}$ and C Culmsee ${ }^{*, 1}$
}

\begin{abstract}
Mitochondrial impairment induced by oxidative stress is a main characteristic of intrinsic cell death pathways in neurons underlying the pathology of neurodegenerative diseases. Therefore, protection of mitochondrial integrity and function is emerging as a promising strategy to prevent neuronal damage. Here, we show that pharmacological inhibition of hypoxia-inducible factor prolyl-4-hydroxylases (HIF-PHDs) by adaptaquin inhibits lipid peroxidation and fully maintains mitochondrial function as indicated by restored mitochondrial membrane potential and ATP production, reduced formation of mitochondrial reactive oxygen species (ROS) and preserved mitochondrial respiration, thereby protecting neuronal HT-22 cells in a model of glutamate-induced oxytosis. Selective reduction of PHD1 protein using CRISPR/Cas9 technology also reduced both lipid peroxidation and mitochondrial impairment, and attenuated glutamate toxicity in the HT-22 cells. Regulation of activating transcription factor 4 (ATF4) expression levels and related target genes may mediate these beneficial effects. Overall, these results expose HIF-PHDs as promising targets to protect mitochondria and, thereby, neurons from oxidative cell death.
\end{abstract}

Cell Death and Disease (2016) 7, e2214; doi:10.1038/cddis.2016.107; published online 5 May 2016

Neurodegenerative diseases such as Alzheimer's disease (AD), Parkinson's disease (PD) and stroke affect millions of people in the ageing societies worldwide and, thus, are of great clinical importance and scientific interest. Although they widely differ in pathology and symptoms, neurodegenerative diseases share common regulated pathways of neuronal cell death underlying manifestation and progression of these diseases. For example, enhanced oxidative stress has been established as a common characteristic and key mediator of neuronal demise. ${ }^{1-3}$ High amounts of reactive oxygen species (ROS) caused by glutamate overload, toxic intracellular $\mathrm{Ca}^{2+}$ concentrations or activation of lipoxygenases (LOX) ${ }^{4,5}$ induce oxidative damage of proteins and lipids at the plasma membrane and in organelles, respectively, thereby leading to regulated cell death. ${ }^{6}$ Mitochondria, in particular, have a pivotal role in this cell death paradigm because they are the key organelles in the energy metabolism and regulation sites of ROS and apoptosis signaling pathways. Mitochondria are major targets of ROS as their membranes and DNAs are easily accessible and accordingly highly vulnerable to oxidative stress. ${ }^{7}$ They also significantly contribute to the additional formation of ROS when their own redox balance is impaired. ${ }^{8}$ Upon damage, mitochondria release proapoptotic proteins such as cytochrome $c$ (Cytc), apoptosis-inducing factor (AIF) and endonuclease $\mathrm{G},{ }^{9,10}$ which leads to cell death. Hence, it is well accepted that mitochondrial damage marks the so-called 'point of no return', ${ }^{10}$ meaning that cells with impaired mitochondria cannot survive. Therefore, protection of mitochondria is a promising strategy against neuronal dysfunction and damage and, therefore, against the manifestation and progression of neurodegenerative diseases.

Recently, hypoxia-inducible factor (HIF) prolyl-4-hydroxylases (PHDs) emerged as promising target candidates for mitochondrial protection in paradigms of oxidative stress. The inhibition of HIF-PHDs prevented neuronal cell death induced by mitochondrial toxins. ${ }^{11}$ In $\mathrm{PHD} 1^{-/-}$myofibers mitochondrial respiration in response to hypoxia was preserved owing to reduced oxidative stress. ${ }^{12}$

HIF-PHDs belong to a family of dioxygenases depending on oxygen, iron and 2-oxoglutarate. They exist in the three isoforms, PHD1, PHD2 and PHD3, and act as oxygen sensors because of their main function being the regulation of HIF expression levels. ${ }^{13}$ However, more and more HIF-independent functions of HIF-PHDs ${ }^{11,14}$ and alternative substrates ${ }^{15-17}$ have been recently identified, which are partly isoform specific. Genetic approaches revealed reduced infarct

\footnotetext{
${ }^{1}$ Institut für Pharmakologie und Klinische Pharmazie, Biochemisch-Pharmakologisches Centrum Marburg, Fachbereich Pharmazie, Philipps-Universität Marburg, Karl-vonFrisch-Straße 1, Marburg 35032, Germany; ${ }^{2}$ Burke-Cornell Medical Research Institute, White Plains, NY, USA and ${ }^{3}$ Feil Family Brain and Mind Research Institute, Department of Neurology and Neuroscience, Weill Medical College, Cornell University, New York, NY, USA

*Corresponding author: C Culmsee, Institut für Pharmakologie und Klinische Pharmazie, Biochemisch-Pharmakologisches Centrum Marburg, Fachbereich Pharmazie, Philipps-Universität Marburg, Karl-von-Frisch-Straße 1, Marburg 35032, Germany. Tel: +49 6421 2825780; Fax: +49 6421 2825720; E-mail: culmsee@ staff.uni-marburg.de Abbreviations: AD, Alzheimer's disease; AIF, apoptosis-inducing factor; ANOVA, analysis of variance; ATF4, activating transcription factor 4; Bid, BH3-interacting domain death agonist; CPO, Ciclopirox; Cytc, cytochrome $c$; DCF, 5,6-chloromethyl-2',7'-dichlorodihydrofluorescein diacetate acetyl ester; DFO, deferoxamine; DHB, ethyl-3,4dihydroxybenzoate; DMOG, dimethyloxalylglycine; elF2 $\alpha$, eukaryotic initiation factor $2 \alpha$; FACS, fluorescence-activated cell sorting; GAPDH, glyceraldehyde 3-phosphate dehydrogenase; GSH, glutathione; HIF, hypoxia-inducible factor; HIF-PHD, HIF-prolyl-4-hydroxylase; LOX, lipoxygenase; MMP, mitochondrial membrane potential; MnSOD, manganese superoxide dismutase; MTT, 3-(4,5-dimethylthiazol-2-yl)-2,5-diphenyltetrazolium bromide; OCR, oxygen consumption rate; PD, Parkinson's disease; ROS, reactive oxygen species; TMRE, tetramethylrhodamine ethyl ester

Received 09.7.15; revised 23.2.16; accepted 22.3.16; Edited by C Munoz-Pinedo
} 
volumes in $\mathrm{PHD}^{-/-}$mice, and exposed improved behavior and less neuronal cell death in the penumbra in $\mathrm{PHD}^{+/-}$mice in a model of transient focal cerebral ischemia. ${ }^{18}$ Further, neuron-specific knockout of PHD2 confirmed neuroprotective effects in the CA1 region after transient cerebral ischemia in mice. ${ }^{19}$ Pharmacological inhibition of HIF-PHDs by iron chelators or 2-oxoglutarate analogs also provided neuroprotection in vitro and in vivo, in models of ischemic neuronal death, ${ }^{20-22} \mathrm{AD},{ }^{11,23} \mathrm{PD}^{24-26}$ and Huntington's disease, ${ }^{11}$ further supporting the pivotal role of HIF-PHDs in neurodegeneration.

To pursue this promising strategy, new HIF-PHD inhibitors have been developed that are more selective than previously available iron chelators such as deferoxamine (DFO) ${ }^{11,14,20}$ and ciclopirox (CPO). ${ }^{11}$ In particular, branched oxyquinolines were identified to inhibit HIF-PHDs via coordination of iron at the active site of HIF-PHDs and modeling shows little predicted interaction with other 2-oxoglutarate-dependent dioxygenases. Additionally, branched oxyquinolines exhibit less iron-chelating properties than $\mathrm{CPO},{ }^{27}$ making it a useful tool to study the effects of selective HIF-PHD inhibition. We named this branched oxyquinoline molecule adaptaquin (AQ) for its ability to inhibit the HIF-PHDs and activate adaptive responses to hypoxia. ${ }^{27}$

In the present study, we investigated the effects of AQ-mediated HIF-PHD inhibition and PHD1 gene silencing on cell viability and, especially, mitochondrial integrity and function in a model of neuronal oxytosis to elucidate the mechanisms leading to AQ-mediated neuronal protection. Oxytosis is defined as oxidative cell death in response to glutamate toxicity, which induces a depletion of glutathione (GSH) and subsequent formation of ROS, resulting in mitochondrial demise and cell death. We found comparable effects of $A Q$ and PHD1 gene silencing on both mitochondrial function and cell viability, suggesting a crucial role for HIFPHDs in mitochondrial impairment and subsequent neurodegeneration induced by oxidative stress.

\section{Results}

PHD1 gene silencing attenuates oxytosis and restores mitochondrial function. In HT-22 cells, high concentrations of extracellular glutamate induce lethal oxidative stress. ${ }^{28}$ This cell death paradigm is known as oxytosis and is characterized by significant morphological and metabolic changes, for example, GSH depletion or activation of LOX. ${ }^{29}$ To study the role of PHD1 in this model system of lethal oxidative stress, we used CRISPR/Cas9 technology to create cells with reduced expression of PHD1 protein. From the initial screening two clones were selected, referred to as clone 2.17 and clone 5.18 below. Western blot analysis (Figure 1a) and subsequent quantification (Figure 1b) revealed significant downregulation of PHD1 protein in both clones compared with wild-type (WT) HT-22 cells. We further analyzed the effects of this downregulation of PHD1 on cell viability and mitochondrial function. PHD1 silencing attenuated glutamate-induced loss of cell viability indicated by MTT (3-(4,5-dimethylthiazol-2-yl)-2,5-diphenyltetrazolium bromide) assay (Figure 1c). This protective effect was permanent at a

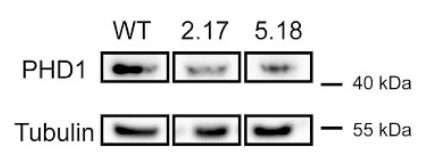

b

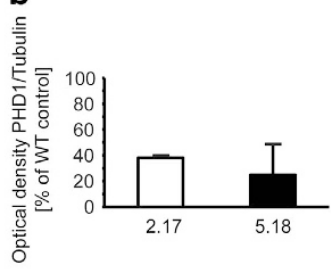

c
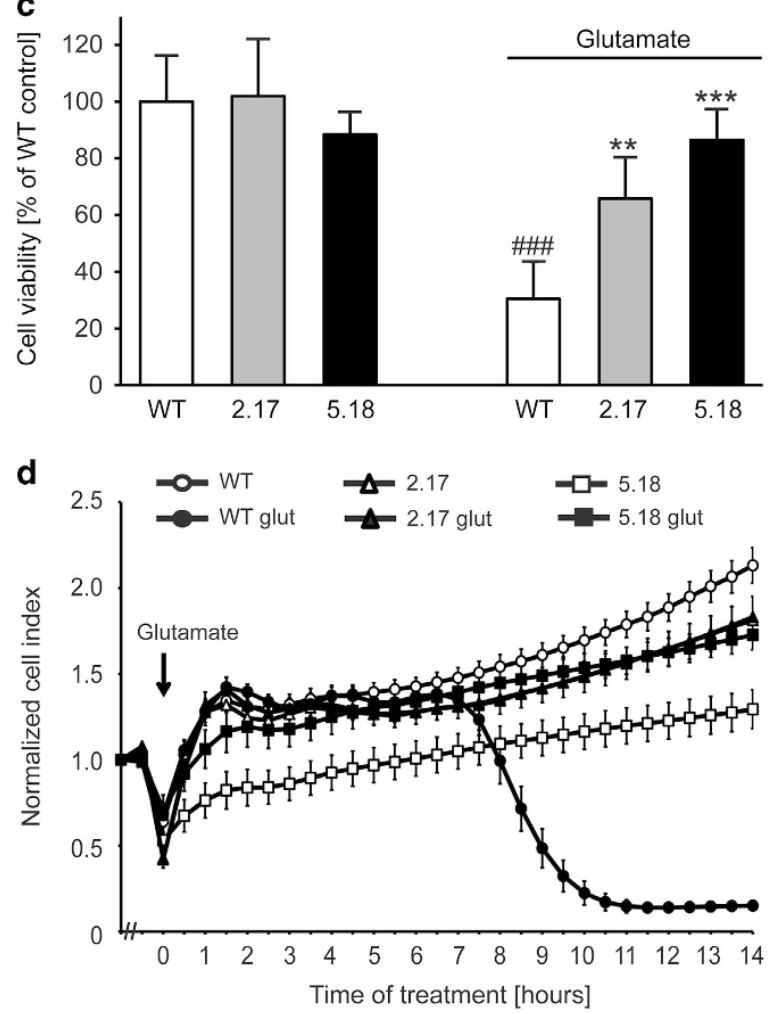

Figure 1 Silencing PHD1 by CRISPR/Cas9 attenuates oxytosis. (a) Selective knockdown of PHD1 by CRISPR/Cas9 was verified by western blot analysis. (b) Quantification of four independent western blots shows a reduction of PHD1 protein level. (c) MTT assay reveals protection of the downregulation of PHD1 by CRISPR/ Cas9 (clones 2.17 and 5.18) against glutamate toxicity $(5 \mathrm{mM}, 16 \mathrm{~h})$ compared with WT cells. Data are given as mean \pm S.D. $(n=8) .{ }^{\# \#} P<0.001$ compared with untreated WT control; ${ }^{* *} P<0.01$ and ${ }^{* * *} P<0.001$ compared with glutamate-treated WT control (ANOVA, Scheffé's test). (d) xCELLigence real-time measurement: downregulation of PHD1 by CRISPR/Cas9 (clones 2.17 and 5.18 ) shows protection against treatment with $7 \mathrm{mM}$ glutamate (glut) compared with WT cells

least for $14 \mathrm{~h}$ of the recording, as further detected by real-time measurements of cellular impedance (Figure 1d).

In the model system of oxytosis, enhanced lipid peroxidation is regarded as a trigger for mitochondrial damage. ${ }^{30}$ Hence, we examined the formation of lipid peroxides after PHD1 gene silencing in the presence and absence of glutamate. BODIPY staining and consequent fluorescence-activated cell sorting (FACS) analysis revealed that PHD1 downregulation prevented lipid peroxidation upon glutamate treatment and did not affect basal levels of lipid ROS (Figure 2a). As it is well established that mitochondrial demise due to elevated ROS levels is a hallmark of oxytosis, ${ }^{30,31}$ mitochondrial ROS formation was then analyzed. To this end, WT HT-22 cells, 
a

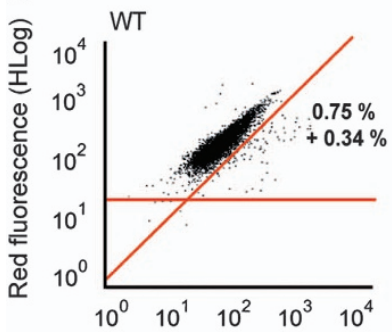

Green fluorescence (HLog)

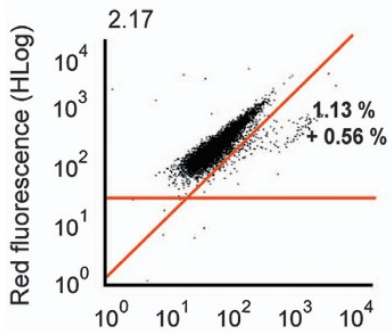

Green fluorescence (HLog)

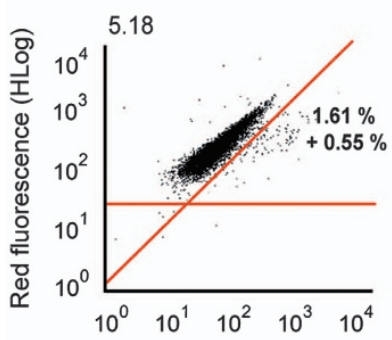

Green fluorescence (HLog)

b

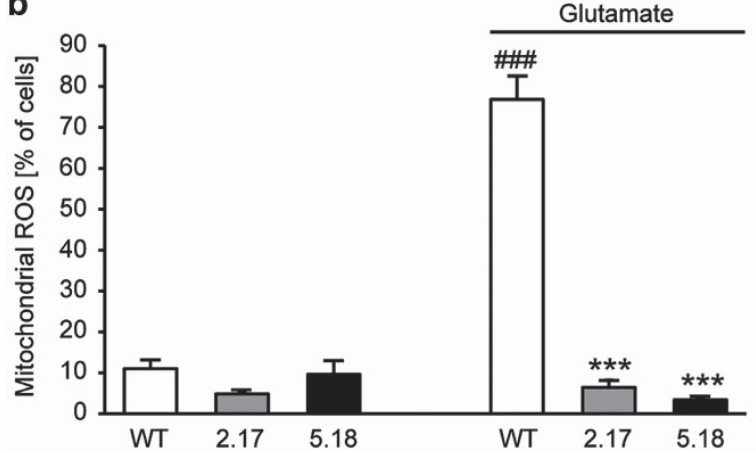

C

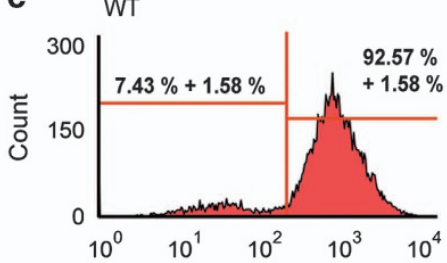

Red fluorescence (RED-HLog)
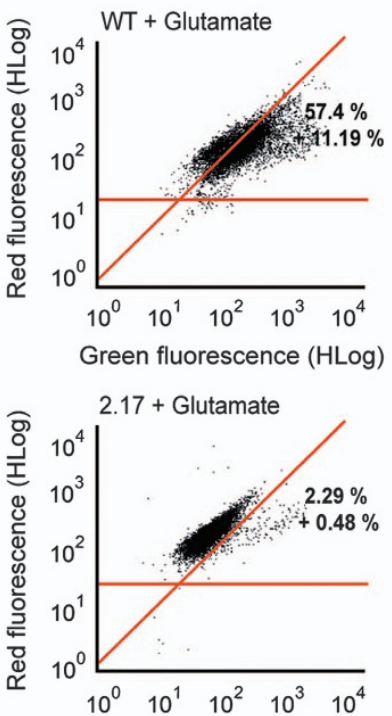

Green fluorescence (HLog)

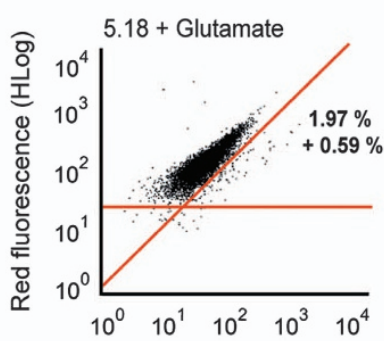

Green fluorescence (HLog)

d

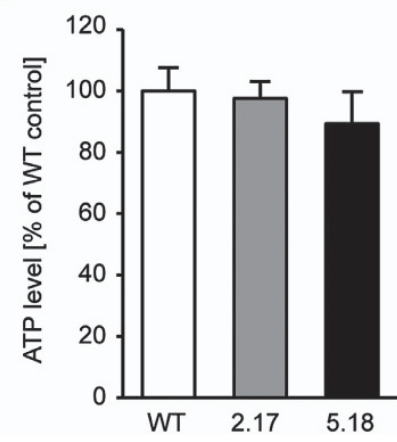

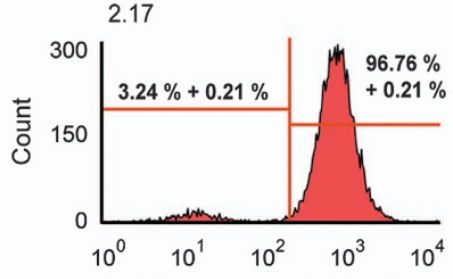

Red fluorescence (RED-HLog)

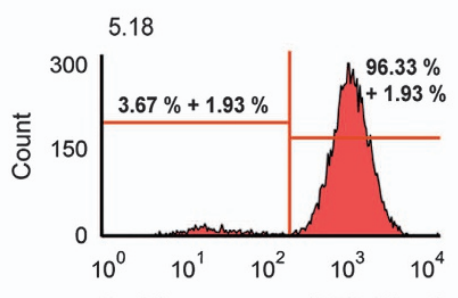

Red fluorescence (RED-HLog)

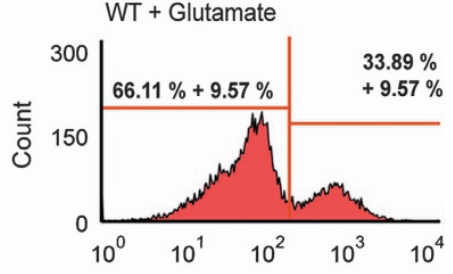

Red fluorescence (RED-HLog)

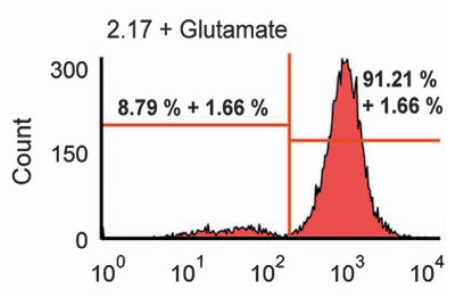

Red fluorescence (RED-HLog)

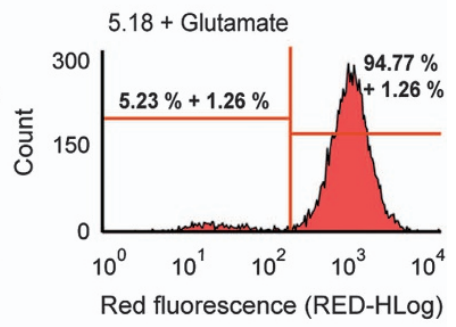

Red fluorescence (RED-HLog)

Glutamate

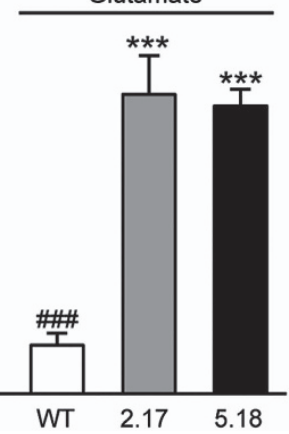

Figure 2 PHD1 silencing by CRISPR/Cas9 restores mitochondrial function and prevents ROS formation. (a) Cells were stained with BODIPY 581/591, a lipophilic fluorescent dye that undergoes a shift from red to green fluorescent emission upon oxidation by free radicals and therefore correlates with the formation of lipid peroxides. Changes of fluorescence were detected by FACS analysis after $15 \mathrm{~h}$ of glutamate treatment ( $7 \mathrm{mM})$. Clones 2.17 and 5.18 showed a significant reduction of the lipid peroxide production compared with WT control cells $(n=4)$. (b) Mitochondrial ROS production was detected by MitoSOX staining and following FACS analysis. Glutamate treatment (7 mM, $15.5 \mathrm{~h}$ ) led to an increase in ROS production. Downregulation of PHD1 by CRISPR/Cas9 (clones 2.17 and 5.18) reduced this increase. Quantification of MitoSOX fluorescence of $n=4$ independent experiments. Data are shown as mean \pm S.D. ${ }^{\# \#} P<0.001$ compared with untreated WT control; ${ }^{* *} P<0.001$ compared with glutamate-treated WT control (ANOVA, Scheffé's test). (c) Representative FACS plots showing that MMP measured by TMRE fluorescence is restored by downregulation of PHD1 by CRISPR/Cas 9 (clones 2.17 and 5.18 ) after glutamate exposure $(6 \mathrm{mM}, 15.5 \mathrm{~h})$. (d) After $15.5 \mathrm{~h}$ of treatment with glutamate (7 mM), ATP levels were measured. PHD1 silencing by CRISPR/Cas9 (clones 2.17 and 5.18) prevented glutamate-induced ATP depletion $(n=8)$. Data are shown as mean \pm S.D. ${ }^{\# \# \# ~} P<0.001$ compared with untreated WT control; ${ }^{\star \star \star} P<0.001$ compared with glutamate-treated WT control. (ANOVA, Scheffé's test)

clone 2.17 and clone 5.18 were treated with glutamate and stained with MitoSOX. Subsequent FACS analysis showed an increase in mitochondrial superoxide formation, which was significantly abolished by PHD1 downregulation (Figure 2b).
As previously described in this system of glutamate toxicity in HT-22 cells, ${ }^{32,33}$ the oxidative cell death is associated with a breakdown of mitochondrial membrane potential (MMP). Measurement of MMP revealed a reduction of mitochondrial 
depolarization by selective PHD1 silencing indicated by restored tetramethylrhodamine ethyl ester (TMRE) fluorescence (Figure 2c). These findings correlated well with the corresponding effects on cell viability. Further, we observed a pronounced loss of ATP after onset of glutamate, which was fully abolished by PHD1 gene silencing (Figure 2d).

To exclude off-target effects, we used siRNA approaches to transiently knockdown PHD1 and performed the same set of experiments. PHD1 siRNA sequences I and II (siPHD I and siPHD II) significantly decreased the mRNA levels of PHD1, while the downregulation at the protein level was not as pronounced (as shown in the western blot in Supplementary Figure 1a). The effect of the siRNAs on PHD1 protein was smaller than the one achieved by the CRISPR/Cas9 technology. Quantification of western blots of five independent experiments confirmed a regulatory effect of the siRNA sequences targeting PHD1 at the protein level, and also showed a high variation of gene silencing efficacy (Supplementary Figure 1b). This partial siRNA-mediated PHD1 downregulation attenuated glutamate-induced loss of cell viability indicated by MTT assay (Supplementary Figures 1c and d). Opposed to the findings in clone 2.17 and 5.18, but in line with the partial downregulation of the PHD1 protein, this protective effect was only transient when detected by realtime measurement of cellular impedance (Supplementary Figures 1e and f). However, knockdown of PHD1 by siRNA approaches attenuated all hallmarks of glutamate-induced oxidative cell death in HT-22 cells, such as the formation of mitochondrial and lipid peroxides, the breakdown of MMP and loss of ATP (Supplementary Figure 2).

$A Q$ protects against glutamate-induced cell death. To further investigate the effects of HIF-PHD inhibition during oxytosis, we used the pharmacological selective HIF-PHDinhibitor AQ. ${ }^{27}$ The glutamate challenge induced established morphological hallmarks of cell death, that is, the cells shrink, round up and detach from the bottom of the culture dish. Cotreatment with $A Q$ fully prevented these morphological features of cell death (Figure $3 a$ ) and preserved cell viability as detected by the MTT assay (Supplementary Figure 3a). A dose-dependent protective effect of $A Q$ was further detected using the xCELLigence system (Roche, Penzberg, Germany; Figure $3 b)$. To establish a therapeutic time window for $A Q$ in the paradigm of glutamate-induced oxytosis, we treated HT-22 cells with the HIF-PHD inhibitor 2 at 4, 6, 8 and $10 \mathrm{~h}$ following the onset of glutamate. Real-time recordings of the cellular impedance demonstrated full protection against oxytosis by post-treatment with $A Q$ up to $4 \mathrm{~h}$ after the onset of glutamate exposure (Supplementary Figure 3b). Notably, even $10 \mathrm{~h}$ after the onset of glutamate, $\mathrm{AQ}$ was able to rescue a significant part of the cells (Figure $3 c$ ), indicating a very strong neuroprotective potential of this particular HIF-PHD inhibitor with an extended post-treatment window of up to $10 \mathrm{~h}$ after onset of oxidative stress.

Glutamate-induced calcium influx is a late-stage event during oxytosis. ${ }^{34}$ Under conditions of extracellular calcium depletion, AQ was still able to prevent glutamate-induced cell death (Supplementary Figure 3c). This observation indicates that $A Q$ does not act via a chelation of calcium and underlines its target specificity.
To confirm the protective effect of HIF-PHD inhibition in the model system of neuronal oxytosis, we next applied different inhibitors of HIF-PHDs, including the 2-oxoglutarate analog ethyl-3,4-dihydroxybenzoate (DHB: 0.1-50 $\mu \mathrm{M}$ ) as well as the iron chelators DFO $(0.1-100 \mu \mathrm{M})$ and CPO (1-20 $\mu \mathrm{M})$. All HIF-PHD inhibitors tested protected HT-22 cells against glutamate-induced oxytosis in a similar manner as $A Q$, which was indicated by preserved cell viability (Figures 3d-f).

AQ preserves mitochondrial respiration. Mitochondria are known to have a key role in cellular life and death, because they are the main source of energy supply, regulation sites for ROS production and key control points for intrinsic pathways of apoptosis. ${ }^{35}$ Impaired energy metabolism due to mitochondrial damage is reflected by reduced ATP levels and loss of MMP, which are regarded as hallmarks of neuronal cell death. ${ }^{1,10}$ To correlate the observed neuroprotective properties of $A Q$ with restored mitochondrial function, we examined the mitochondrial respiratory capacity and ATP production by measuring the oxygen consumption rate (OCR) using the Seahorse XF96 system (Seahorse Biosciences, North Billerica, MA, USA). The glutamate challenge decreased both the basal and maximal respiration reflected by a reduced OCR. These detrimental metabolic changes were abolished by cotreatment with $A Q$ (Figure 4a), which, furthermore, restored the mitochondrial ATP production (Figure 4b).

Owing to the very pronounced effect of $A Q$ on cell viability, as well as mitochondrial integrity, we were interested to find out if this particular HIF-PHD inhibitor was capable of preventing glutamate-induced GSH depletion, which is the starting point of oxidative stress and oxytosis. To this end, we examined the levels of GSH after the glutamate challenge in the presence and absence of AQ. Similar to previous findings, ${ }^{29,34}$ glutamate (5 $\mathrm{mM}$ ) induced a rapid and sustained decrease of GSH levels within $2 \mathrm{~h}$ and up to $10 \mathrm{~h}$ of exposure. Notably, we were not able to detect GSH levels in HT-22 cells after $10 \mathrm{~h}$ of glutamate exposure because the GSH levels dropped below detection limits. Surprisingly, although AQ fully protected HT-22 cells from cell death and morphological changes, it failed to rescue the observed drop of GSH levels (Figure 4c). These findings indicated that HIF-PHD inhibition provided neuroprotective effects downstream of GSH depletion, and GSH restauration was dispensable for the protective effects.

The other aforementioned HIF-PHD inhibitors exhibited similar effects upstream and at the level of mitochondria as observed for AQ. DFO, DHB and CPO prevented glutamateinduced lipid peroxidation (Figure 5a) and subsequent formation of mitochondrial ROS (Figure $5 b$ ), while none of the inhibitors affected any of these parameters under basal conditions. Furthermore, DFO, DHB and CPO fully restored ATP levels (Figure $5 \mathrm{c}$ ) and the MMP examined via TMRE staining (Figure $5 d$ ). Similar to the effects obtained with $A Q$, DFO, DHB and CPO also maintained both, basal and maximal mitochondrial respiration (Figure $5 \mathrm{e}$ ). These observations suggest an almost intact mitochondrial function upon inhibition of HIF-PHDs in the presence as well as in the absence of glutamate, which correlates well with the observed protection of cell viability. 
a
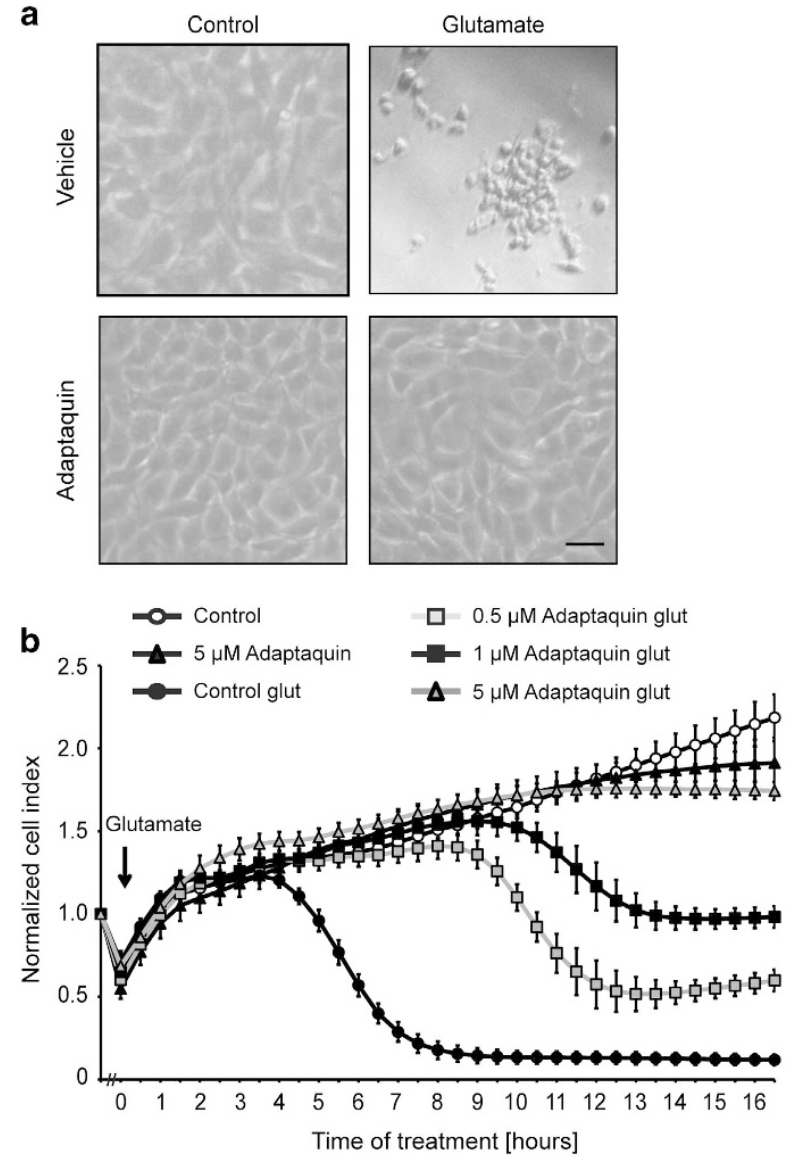

C

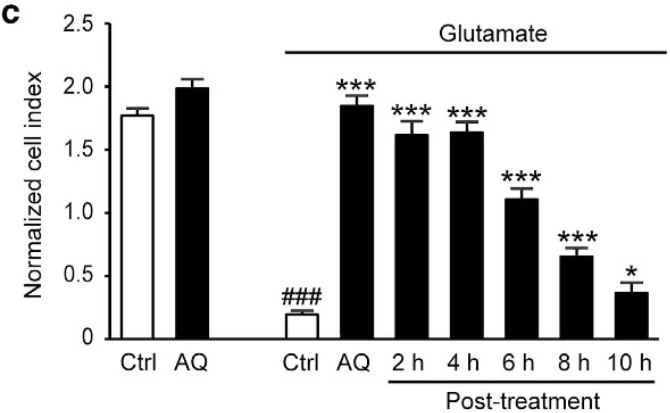

Glutamate

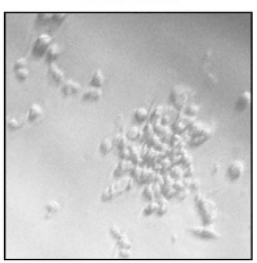

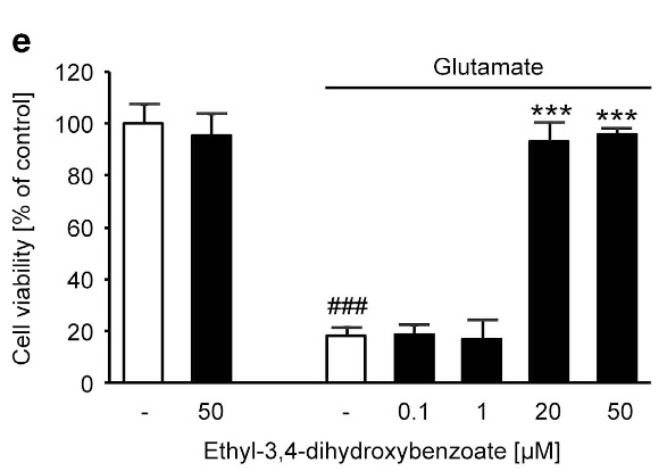
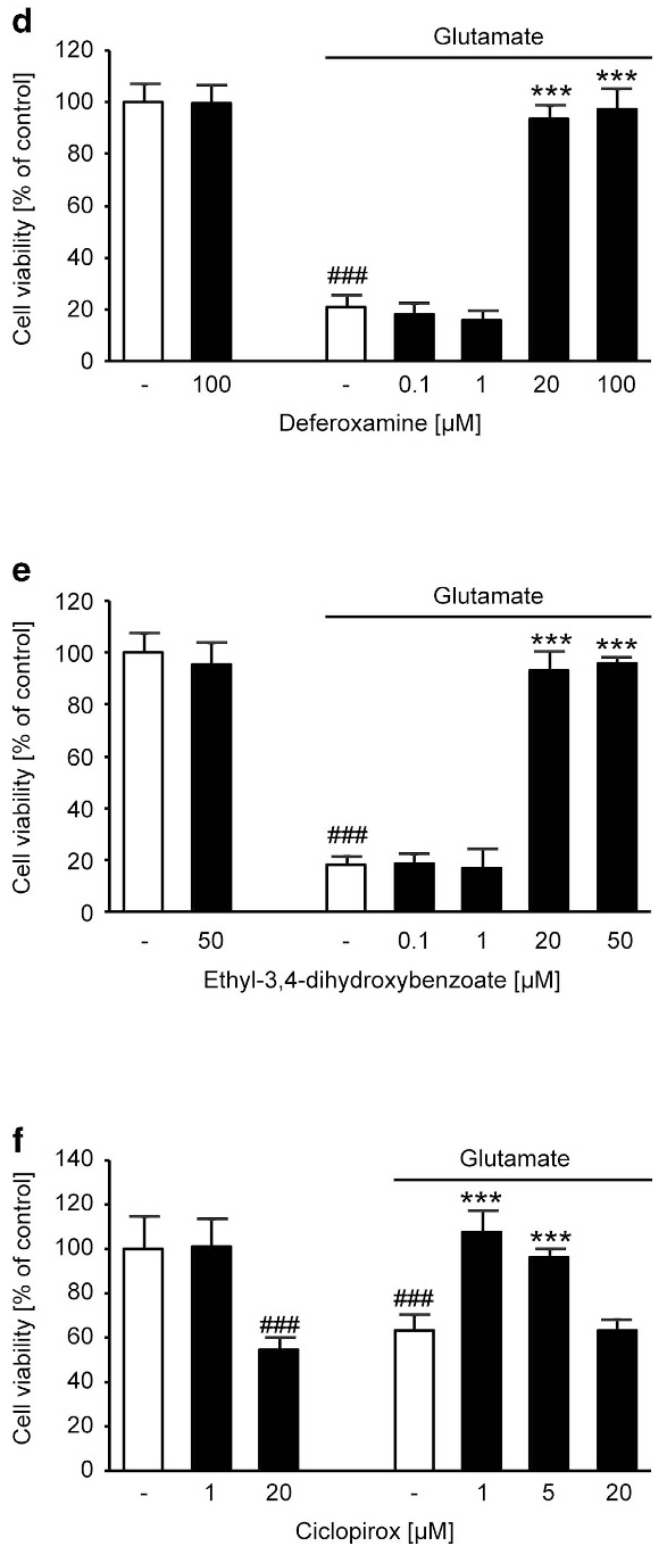

Figure 3 PHD inhibitors protect against oxytosis. (a) Light microscopy pictures show altered morphology of glutamate-treated ( $5 \mathrm{mM}, 15 \mathrm{~h}) \mathrm{HT}-22 \mathrm{cells}$. Cotreatment with AQ $(2 \mu \mathrm{M})$ fully prevents these changes. Scale bar: $50 \mu \mathrm{m}$. (b) xCELLigence real-time impedance measurement shows dose-dependent salutary effect of $A Q(n=6)$. (c) Bar graph evaluation at the $15.5 \mathrm{~h}$ time point from xCELLigence recordings (Supplementary Figure $3 \mathrm{~b}$, right black arrow) under post-treatment conditions $(n=6)$. ${ }^{\# \# ~} P<0.001$ compared with untreated control; ${ }^{*} P<0.05$ and ${ }^{* * \star} P<0.001$ compared with glutamate-treated control (ANOVA Scheffé's test). (d-f) MTT assays show protective effects of different concentrations of DFO (d), DHB (e) and CPO (f) against glutamate-induced (7 mM, $16 \mathrm{~h})$ oxytosis $(n=8)$. Data are given as mean \pm S.D. ${ }^{\# \# \# ~} P<0.001$ compared with untreated control; ${ }^{* \star} P<0.001$ compared with glutamate-treated control (ANOVA Scheffe's test)

$A Q$ shows antioxidative properties independent of MnSOD. As GSH is the main antioxidant in the brain, it has a crucial role for detoxification of ROS and a disturbed GSH metabolism has been associated with neurodegenerative diseases. ${ }^{36}$ The question arose of how can $A Q$ mediate neuroprotection despite impaired GSH levels. To address this question, we analyzed the formation of soluble ROS $6 \mathrm{~h}$ after the onset of glutamate treatment to identify possible antioxidative characteristics of $\mathrm{AQ}$. To this end, HT-22 cells were stained with $\mathrm{CM}-\mathrm{H}_{2}$ DCFDA (5,6-chloromethyl-2', $7^{\prime}$ dichlorodihydrofluorescein diacetate acetyl ester), a fluorescent dye that shows green fluorescence upon oxidation by soluble ROS. After $6 \mathrm{~h}$ of glutamate exposure, we saw an increase in green fluorescence, indicating enhanced formation of ROS (Figure 6a), which correlates well with the results of the GSH measurements. Hence, AQ reduced this effect, but was not able to fully abolish it (Figure 6b). This suggests some antioxidative properties, which were further supported 

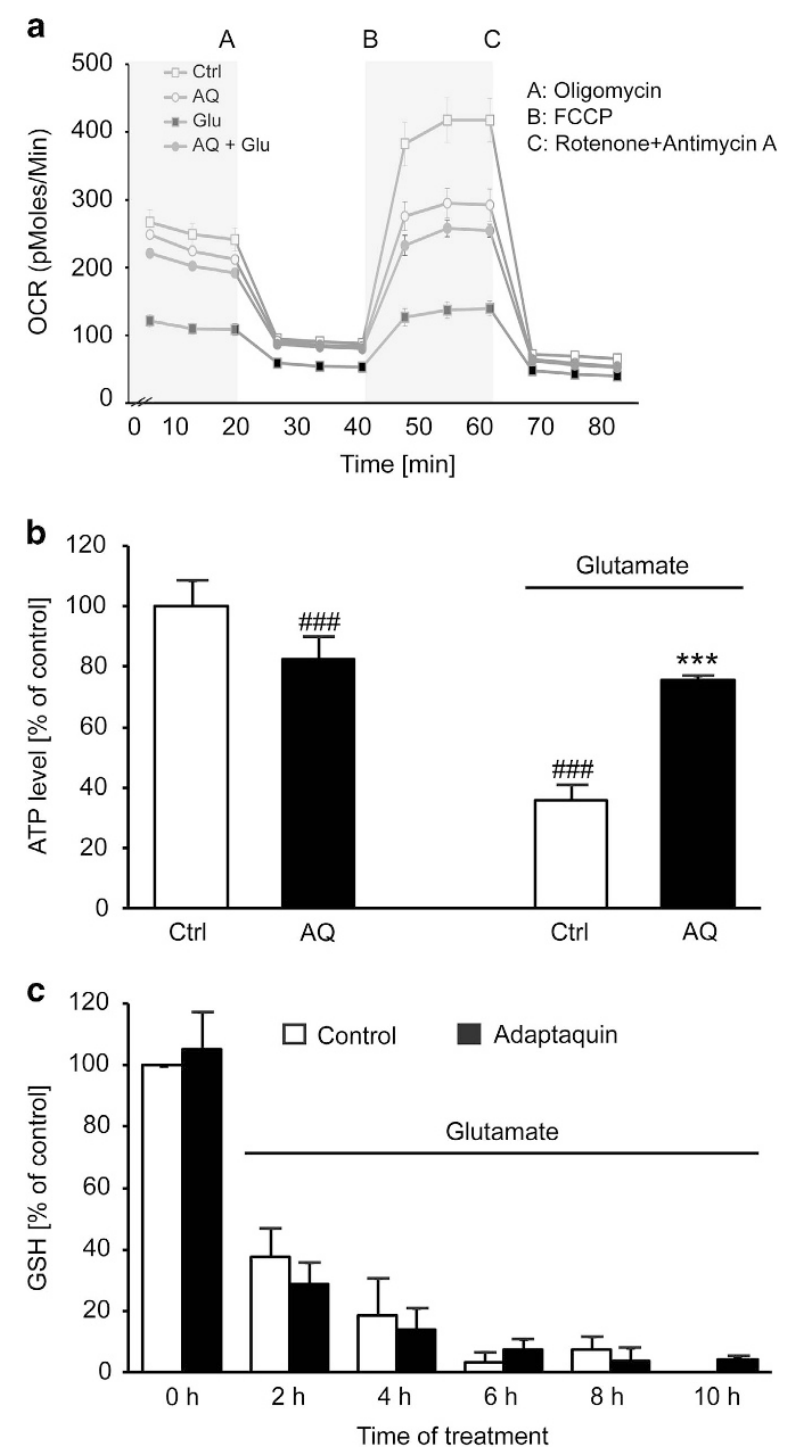

Figure $4 \mathrm{AQ}$ preserves mitochondrial respiration. (a) Measurement of the OCR reveals restored basal and maximal respiration by $A Q(2 \mu \mathrm{M})$ after glutamate exposure (4 mM, $15 \mathrm{~h}$ ). (b) Quantification of ATP production from (a) calculated as difference between average OCR in section A (light gray) and section B (white) shows loss of ATP after glutamate exposure. AQ prevents decrease of ATP levels $(n=6)$. Data are given as mean \pm S.D. ${ }^{\# \# \# ~} P<0.001$ compared with untreated control; ${ }^{* * *} P<0.001$ compared with glutamate-treated control (ANOVA Scheffé's test). (c) Measurement of GSH depicts rapid decrease of GSH after glutamate exposure $(5 \mathrm{mM})$, which is not restored by cotreatment with $\mathrm{AQ}(2 \mu \mathrm{M})$ by a dose-dependent protection against $\mathrm{H}_{2} \mathrm{O}_{2}$-induced cell death (Figure $6 \mathrm{c}$ ). However, these partial antioxidative effects cannot fully explain the mitochondrial protection, and, therefore, we also checked for changes in the expression of the manganese superoxide dismutase (MnSOD). MnSOD is known to be part of the antioxidative defense of mitochondria and its overexpression has been shown to reduce oxidative damage in HT-22 cells. $^{28}$ Interestingly, glutamate induced a strong increase in MnSOD levels while they remained almost unchanged after treatment with $A Q$ (Supplementary Figure 4a). Thus, suggesting that $A Q$ does not mediate protection against glutamate by enhancing the antioxidative defense machinery of mitochondria. The glutamate-induced upregulation of MnSOD indicates a compensatory effect of the damaged cells to cope with enhanced oxidative stress. ${ }^{37}$

AQ alters ATF4 expression. As ATF4 has been shown to correlate with oxidative stress ${ }^{38,39}$ and also to regulate and interact with HIF-PHDs, ${ }^{40,41}$ we examined the expression of ATF4 upon glutamate exposure to further elucidate the mechanism of AQ-mediated protection. ATF4 expression increased $4 \mathrm{~h}$ after the onset of glutamate treatment and decreased at $14 \mathrm{~h}$. This downregulation associated with glutamate-induced death was fully prevented by HIF-PHD inhibition (Figure 7a). A similar expression pattern after $14 \mathrm{~h}$ of glutamate exposure was found for the $\mathrm{xCT}$, which was recently shown to be regulated by ATF4 in HT-22 cells. ${ }^{42}$ After $14 \mathrm{~h}$ of glutamate treatment, XCT levels declined, while cotreatment with $A Q$ restored $x C T$ expression levels at this time point (Figure $7 \mathrm{~b}$ ). To determine if the regulation of $x \mathrm{CT}$ was driven via the eukaryotic initiation factor $2 a$ (elF2a)/ATF4 pathway, we investigated the phosphorylation state of elF2 $a$ at both 4 and $14 \mathrm{~h}$ after the onset of the glutamate treatment. The phosphorylation of elF2a seemed to be transiently enhanced at $4 \mathrm{~h}$ in the presence of $A Q$ irrespective of glutamate exposure. After $14 \mathrm{~h}$, none of the treatment conditions induced significant changes in the phosphorylation state of elF2a (Figure 7c). Overall, these data imply that the alterations in $\mathrm{xCT}$ expression levels may be mediated through ATF4, but are not induced via the elF2a/ATF4 pathway.

ATF4 expression is not required for AQ-mediated protection. To answer the question of whether the restoration of ATF4 expression induced by $A Q$ after $14 \mathrm{~h}$ of glutamate challenge was required for the protective effect, we analyzed cell viability after siRNA-mediated gene silencing of ATF4. Surprisingly, AQ still protected ATF4-silenced cells against

\footnotetext{
Figure 5 PHD inhibitors preserve mitochondrial function and prevent generation of mitochondrial and lipid peroxides. (a) DFO (20 $\mu \mathrm{M})$, DHB (20 $\mu \mathrm{M})$ and CPO $(2 \mu \mathrm{M})$ abolish glutamate-induced $(7 \mathrm{mM}, 15 \mathrm{~h}$ ) formation of lipid peroxides measured by BODIPY staining and subsequent FACS analysis. Data are given as mean \pm S.D. ( $n=4)$. ${ }^{\# \# \# ~} P<0.001$ compared with untreated control; ${ }^{* \star} P<0.001$ compared with glutamate-treated control (ANOVA Scheffé's test). (b) DFO (20 $\left.\mu \mathrm{M}\right), \mathrm{DHB}(20 \mu \mathrm{M})$ and CPO $(2 \mu \mathrm{M})$ prevent generation of mitochondrial ROS upon glutamate treatment $(7 \mathrm{mM}, 15 \mathrm{~h})$. Data are given as mean \pm S.D. ${ }^{\# \# \#} P<0.001$ compared with untreated control; ${ }^{* * *} P<0.001$ compared with glutamate-treated control (ANOVA Scheffé's test). (c) Different concentrations of DFO, DHB and CPO prevent glutamate-induced (7 mM, $15 \mathrm{~h}$ ) loss of ATP. Data are given as mean \pm S.D. $(n=8)$. ${ }^{\# \# \#} P<0.001$ compared to untreated control; ${ }^{* \star} P<0.001$ compared to glutamate-treated control; ANOVA Scheffé's test. (d) DFO (20 $\mu$ M), DHB $(20 \mu \mathrm{M})$ and CPO $(2 \mu \mathrm{M})$ fully prevent breakdown of MMP after glutamate challenge $(7 \mathrm{mM}, 15 \mathrm{~h})$. Data are given as mean \pm S.D. $(n=4)$. ${ }^{\# \#} P<0.001$ compared with untreated control; ${ }^{* \star \star} P<0.001$ compared with glutamate-treated control; ANOVA Scheffe's test. (e) Measurement of the OCR after glutamate exposure $(4 \mathrm{mM}, 15 \mathrm{~h})$ shows decrease of the basal and maximal respiration, which was prohibited by DFO $(20 \mu \mathrm{M})$, DHB $(20 \mu \mathrm{M})$ and CPO $(2 \mu \mathrm{M})$, respectively
} 
glutamate-induced cell death. Notably, siRNA-mediated ATF4 downregulation itself resulted in pronounced cytotoxicity, which was completely abolished by $A Q$ (Figures $8 a$ and b).
Such toxic effects by ATF4 gene silencing can likely be attributed to the enhanced formation of soluble ROS, which occurred in a time-dependent manner in HT-22 cells after
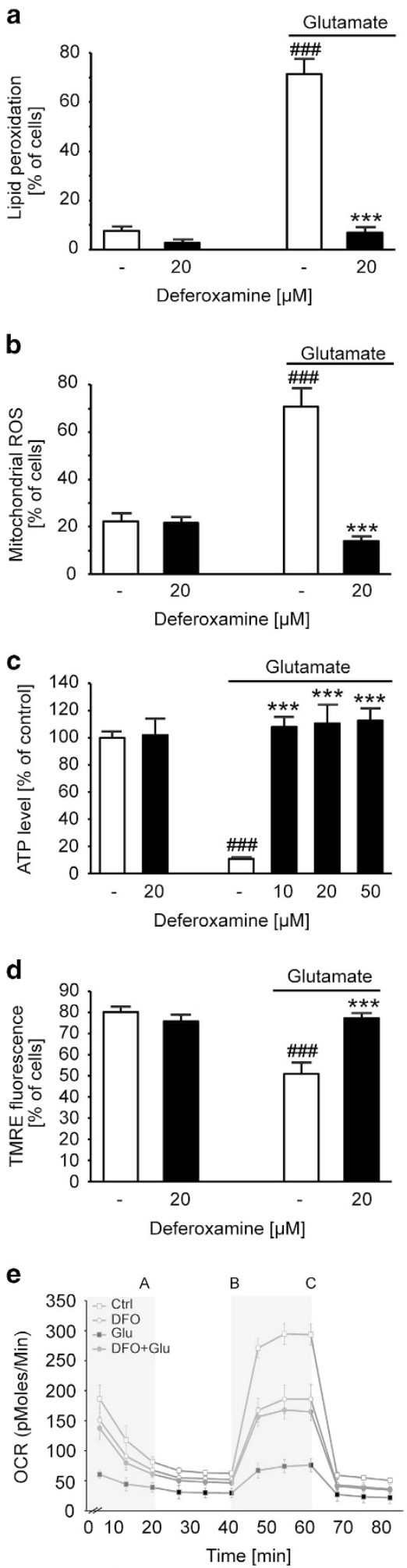

A: Oligomycin

B: FCCP

C: Rotenone+Antimycin A
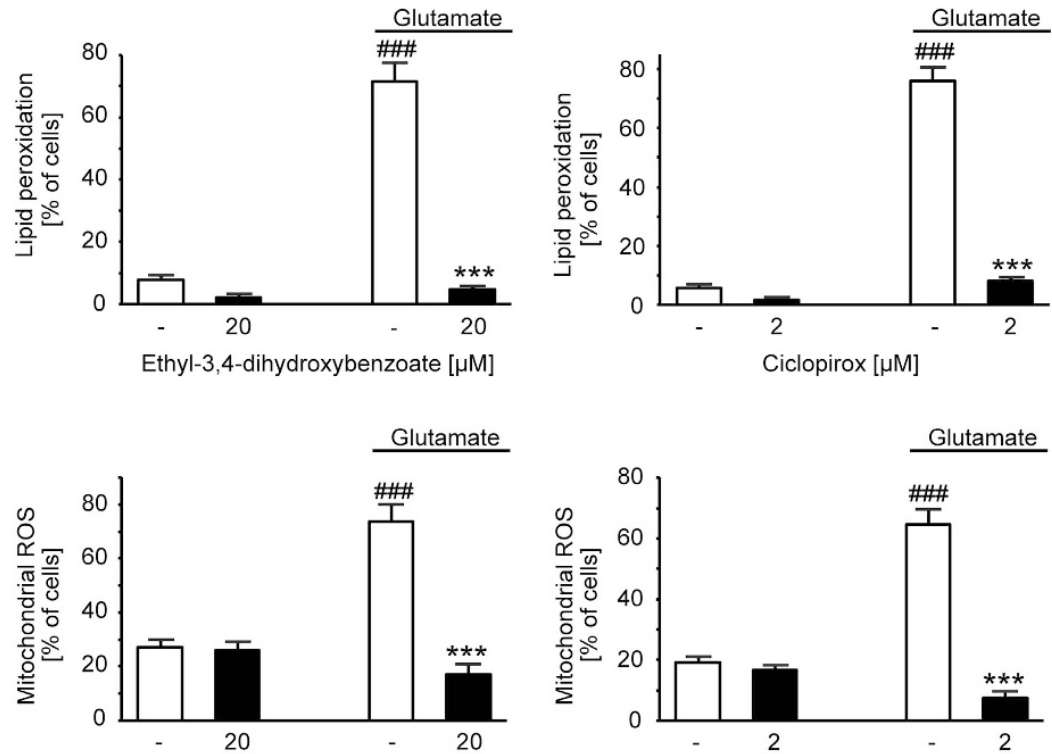

Ethyl-3,4-dihydroxybenzoate $[\mu \mathrm{M}]$
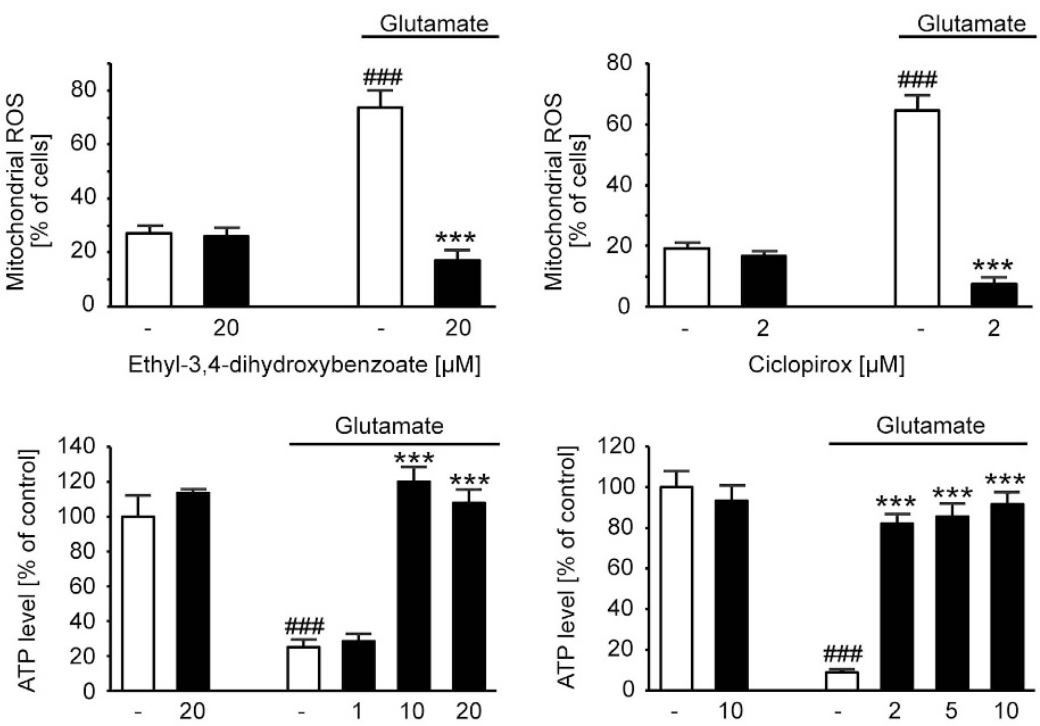

Ethyl-3,4-dihydroxybenzoate $[\mu \mathrm{M}]$
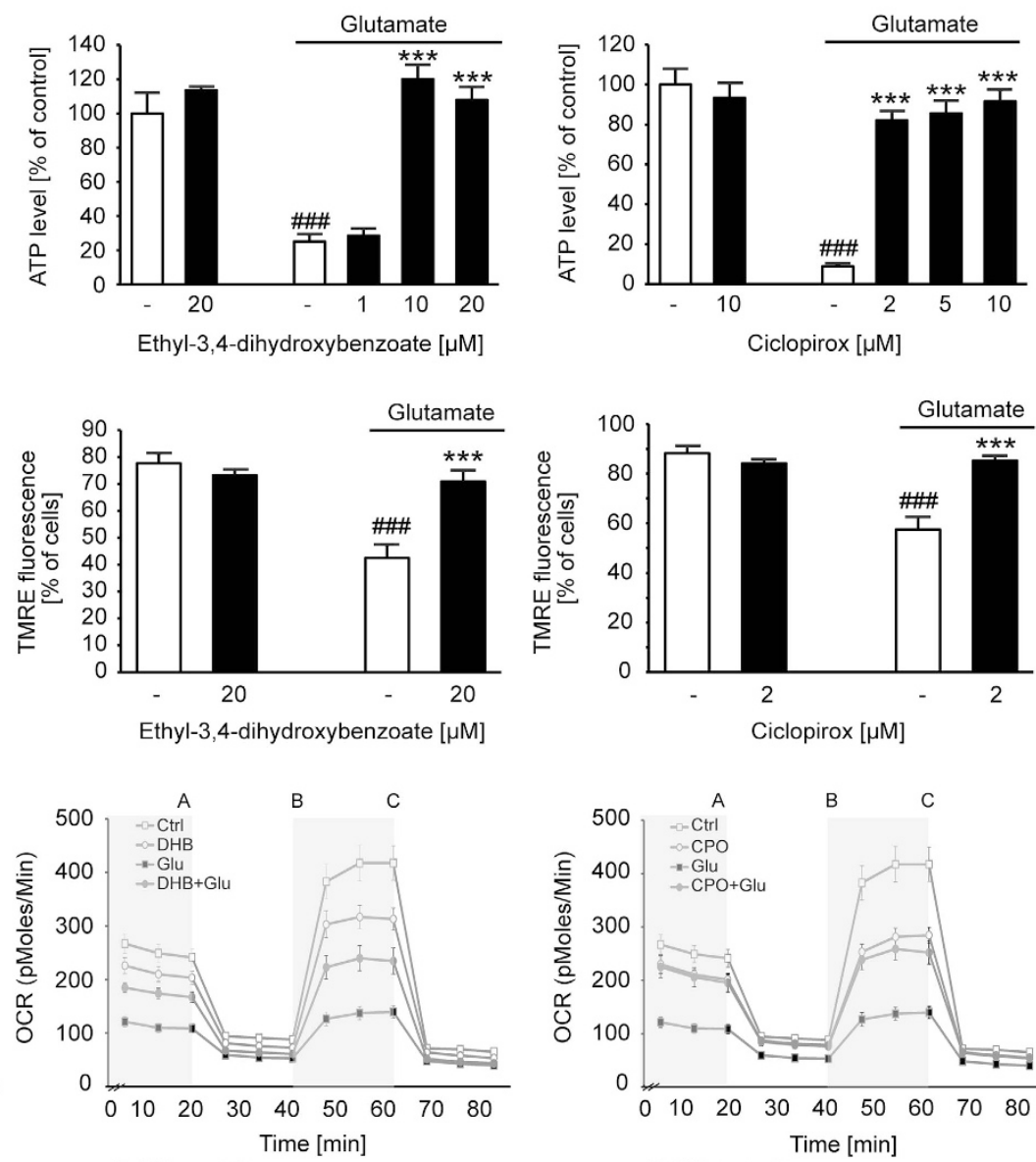

A: Oligomycin

B: FCCP

C: Rotenone+Antimycin A

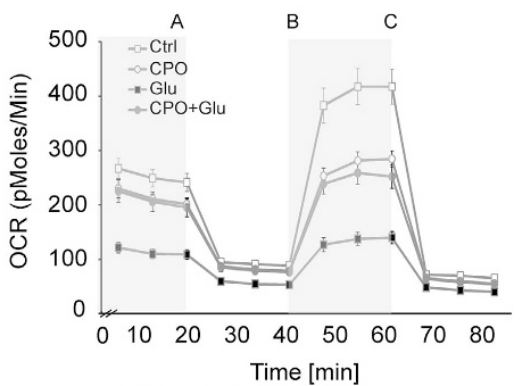

A: Oligomycin

B: FCCP

C: Rotenone+Antimycin A 

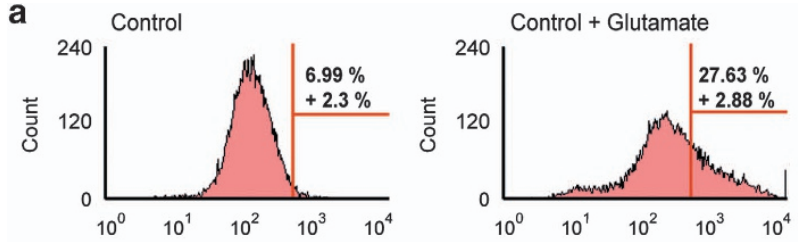

Green fluorescence (RED-HLog) Adaptaquin

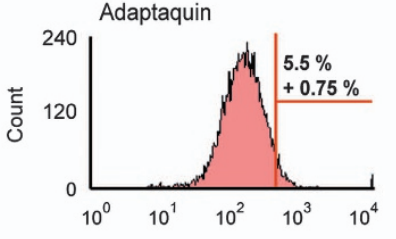

Green fluorescence (RED-HLog)

Adaptaquin + Glutamate

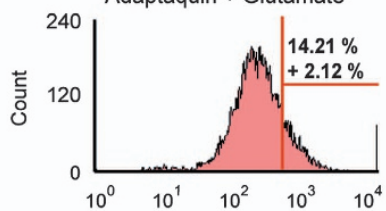

Green fluorescence (RED-HLog)

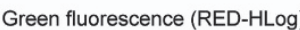

b
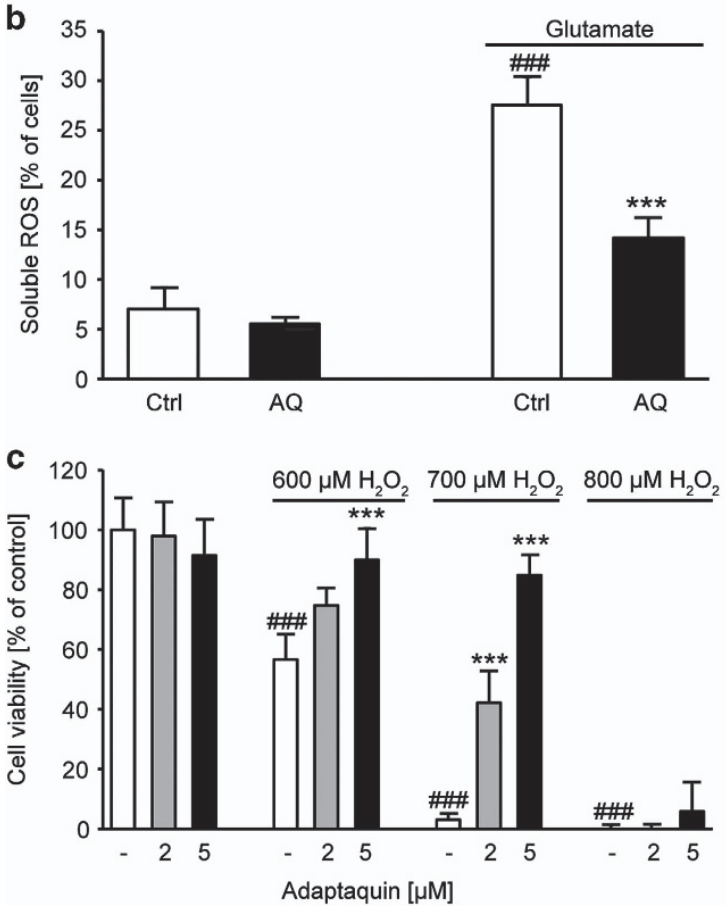

Figure 6 AQ shows small antioxidative properties. (a) DCF staining shows formation of soluble ROS after $6 \mathrm{~h}$ of glutamate $(4 \mathrm{mM})$ challenge. Cotreatment with $\mathrm{AQ}(2 \mu \mathrm{M})$ reduces soluble ROS. (b) Quantification of DCF fluorescence of $n=3$ independent experiments shown in the representative plots in (a). Data are shown as mean \pm S.D. ${ }^{\# \# \# ~} P<0.001$ compared with untreated control; ${ }^{\star \star \star} P<0.001$ compared with glutamate-treated control; ANOVA, Scheffé's test. (c) MTT assay shows dosedependent protection of $A Q$ against $\mathrm{H}_{2} \mathrm{O}_{2}$-induced cell death (16 h). Data are shown as mean \pm S.D. $(n=8) .{ }^{\# \# \#} P<0.001$ compared with untreated control; ${ }^{* \star *} P<0.001$ compared with respective $\mathrm{H}_{2} \mathrm{O}_{2}$-treated control; (ANOVA, Scheffé's tes)

incubation with ATF4 siRNA (Figure 8c). Cotreatment with AQ during transfection prevented this formation of ROS by ATF4 silencing (Figure 8d). Overall, these data suggest that the observed AQ-mediated upregulation of ATF4 was dispensable for the protective effect of the HIF-PHD inhibitor.

\section{Discussion}

The present study clearly depicts that both pharmacological inhibition and gene silencing of HIF-PHDs prevent mitochondrial impairment and cell death in a model of neuronal oxytosis. Our results on cell viability confirm previous findings for PHD1 silencing and the HIF-PHD inhibitors DFO, $\mathrm{DHB}$ and $\mathrm{CPO}$ in similar models of neuronal oxidative stress. ${ }^{14,20,43}$ Protective effects of DFO and dimethyloxalylglycine (DMOG) against glutamate toxicity, and of DFO, DHB and CPO against 3-nitropropionic acid, ${ }^{11}$ were previously also obtained in HIF-1a-silenced cells. ${ }^{14,44}$ Beyond previous findings, our study now demonstrates that HIF-PHD inhibitors exert protective effects at the level of mitochondria. Results from previous studies suggest that HIF-1a-independent mechanisms contribute to the protection of mitochondria. The identification of additional targets of HIF-PHDs besides HIF-1a, such as the large subunit of RNA polymerase ${ } \mathrm{I}^{16}$ and cyclin D1, ${ }^{17}$ and the presence of HIF-PHDs in organisms not expressing HIF isoforms further support the conclusion of HIFindependent functions of HIF-PHDs. ${ }^{45}$ Moreover, HIF-1a is predominantly regulated by PHD2. ${ }^{46}$ Nevertheless, in our system we achieved both the protection of cell viability and mitochondrial integrity by silencing PHD1 without regulating the mRNA level of PHD2 (Supplementary Figure 1a), which facilitated an HIF-independent mechanism of protection. Further, Aragonés et al. ${ }^{12}$ also showed that PHD1 deficiency reduced the formation of oxidative stress and preserved mitochondrial function after ischemia in skeletal muscle fibers, thereby leading to hypoxia tolerance independently of HIFinduced adaptive effects.

The conservation of mitochondrial function as a crucial mechanism of neuronal protection has widely been shown in $\mathrm{AD}^{47}$ and $\mathrm{PD}^{48}$ models as well as in humans. ${ }^{49}$ Our present data suggest that mitochondrial protection also has a central role in AQ- and PHD1 CRISPR/Cas9- or siRNA-mediated protection of HT-22 cells. During oxidative stress, mitochondrial demise is induced by the transactivation of the proapoptotic protein $\mathrm{BH} 3-$ interacting domain death agonist (Bid) via ROS. ${ }^{9}$ In HT-22 cells, these ROS result from lipid peroxidation ${ }^{5,30}$ due to GSH depletion. ${ }^{34}$ Both silencing PHD1 and $A Q$ abolished the formation of lipid peroxides, indicating an action upstream of mitochondria and leading to mitochondrial protection. Despite the pronounced neuroprotective effect, $A Q$ was unable to prevent the glutamate-induced decrease of GSH levels below detection limits. This observation is in line with previous findings where full protection of HT-22 cells was achieved despite fully depleted GSH levels. ${ }^{34,50}$ Taken together, these results suggest an influence of HIF-PHD inhibition by AQ at the level of 12/15-LOXs. This can not only be explained by the iron-chelating effects or offtarget inhibition of these enzymes, as PHD1 gene silencing also reduced lipid peroxidation (Figure $2 \mathrm{a}$ and Supplementary Figure 2a). Further, structural analyses revealed that $A Q$ did not fit to the active center of 12-LOX. ${ }^{27}$ A possible explanation for the activity of HIF-PHD inhibition on LOX activities was recently provided by Karuppagounder and Ratan ${ }^{51}$ who proposed a suppression of 12-LOX expression upon inhibition of HIF-PHDs. This suppression has been attributed to modification of RNA polymerase $1{ }^{51}$ Downregulation of 12/15-LOX expression after both AQ treatment and PHD1 knockdown further facilitated this assumption (Supplementary Figures $4 b-d)$. 
a
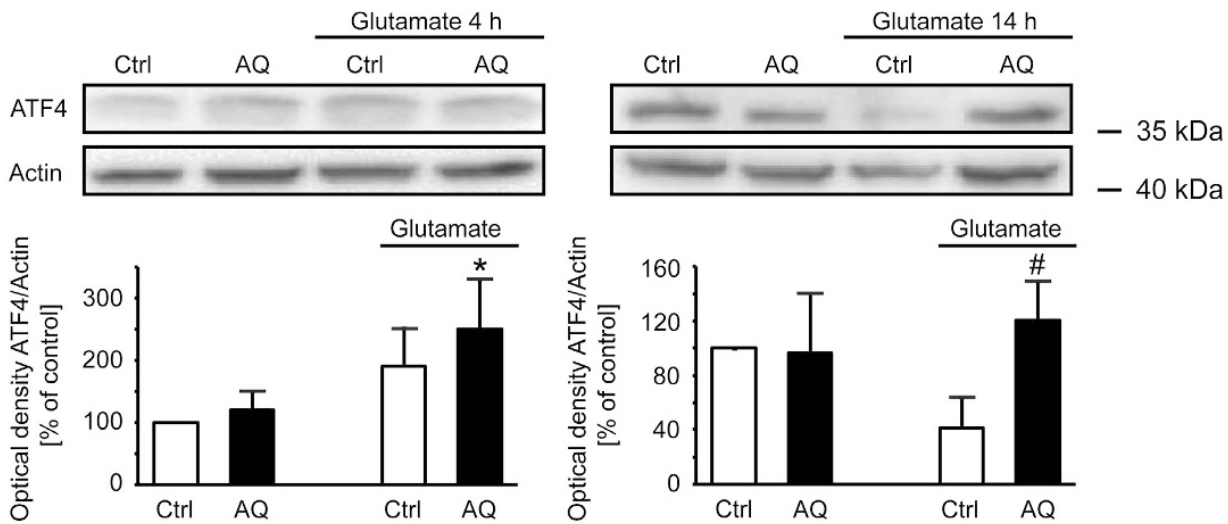

b
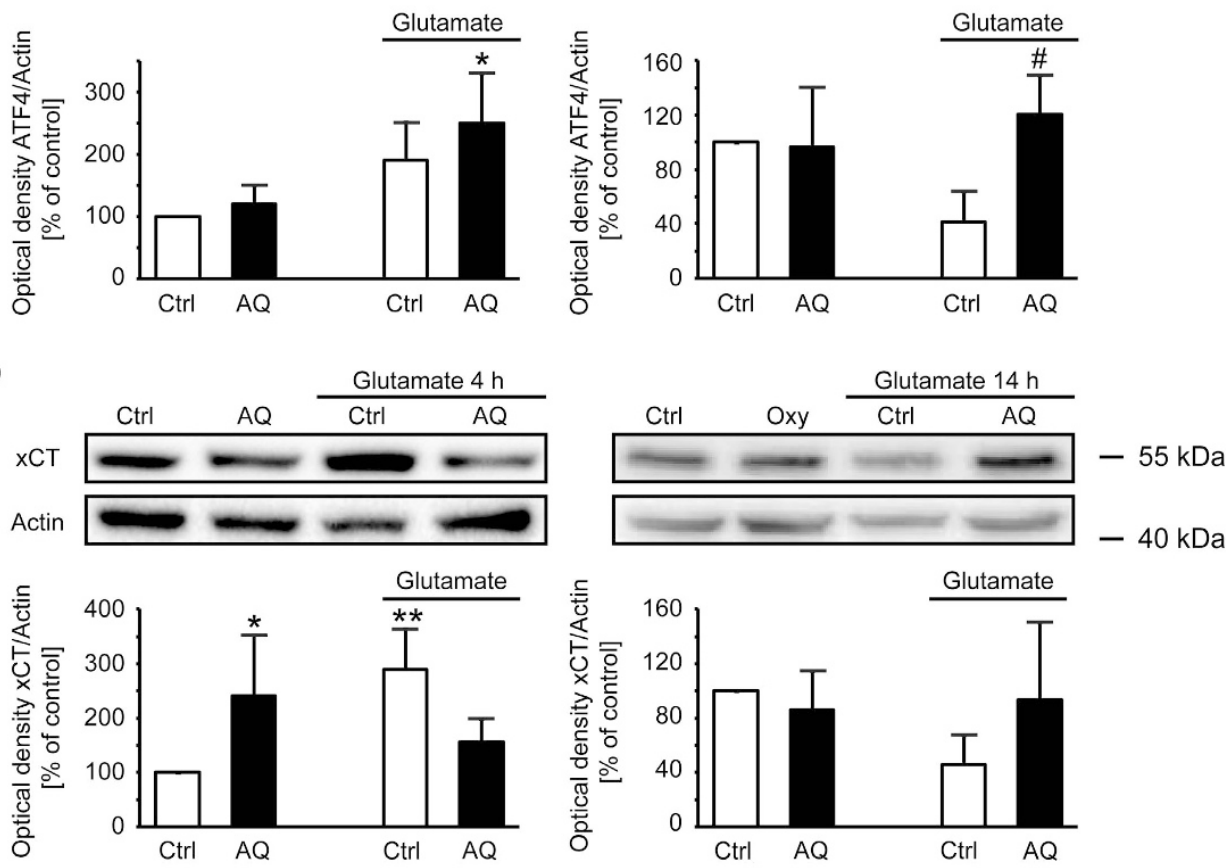

C
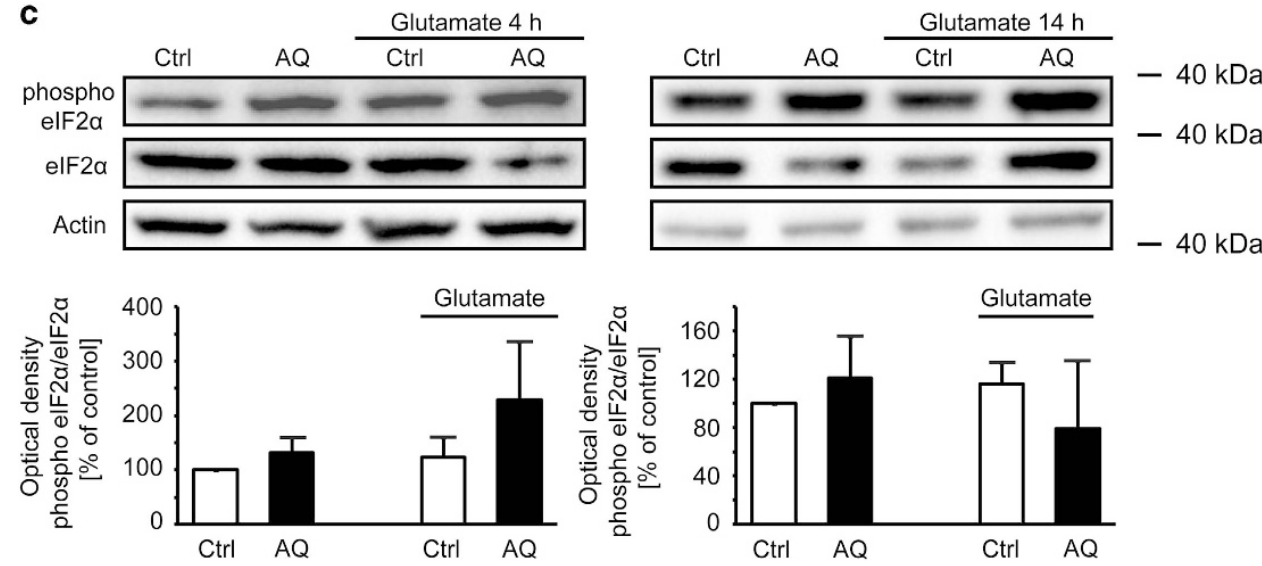

Figure $7 \mathrm{AQ}$ regulates ATF4 expression. (a) Representative western blots and corresponding quantifications of four independent experiments show upregulation of ATF4 after $4 \mathrm{~h}$ of glutamate and downregulation after $14 \mathrm{~h}$, which is restored by $\mathrm{AQ} .{ }^{\#} P<0.05$ compared with glutamate-treated control. (b) Representative western blots and corresponding quantifications of four independent experiments reveal upregulation of $x C T$ after $4 \mathrm{~h}$ of glutamate and downregulation after $14 \mathrm{~h}$, which is restored by $A Q$. ${ }^{*} P<0.05$ and ${ }^{* *} P<0.01$ compared with untreated control. (c) Representative western blots and corresponding quantification do not indicate significant changes of the phosphorylation state of elF2 $\alpha$ upon glutamate challenge or treatment with $A Q$

In our system, both PHD1 gene silencing by CRISPR/Cas9 and the use of pharmacological approaches permanently protected HT-22 cells. In contrast, knockdown of PHD1 by siRNA only showed partial protective effects. Apparently, the transient knockdown via siRNA results in a residual activity of the enzyme, which is sufficient enough to promote cell death. Further, inhibition of PHD1 may improve oxygen radical detoxification and accordingly reduced detection of lipoxygenation through shunting glucose into the pentose phosphate pathway, as recently demonstrated in $\mathrm{PHD}^{-/-}$ neurons and in a model of cerebral ischemia in vivo. ${ }^{52}$ Further studies should reveal whether such reprogramming of the glucose metabolism is also involved in the protective effects of $A Q$ and other PHD inhibitors in paradigms of oxidative cell death and at the level of mitochondria.

The pharmacological HIF-PHD inhibitors do not act on specific isoforms of the enzyme, suggesting that also inhibition of PHD2 and PHD3 may contribute to the protective effects of 

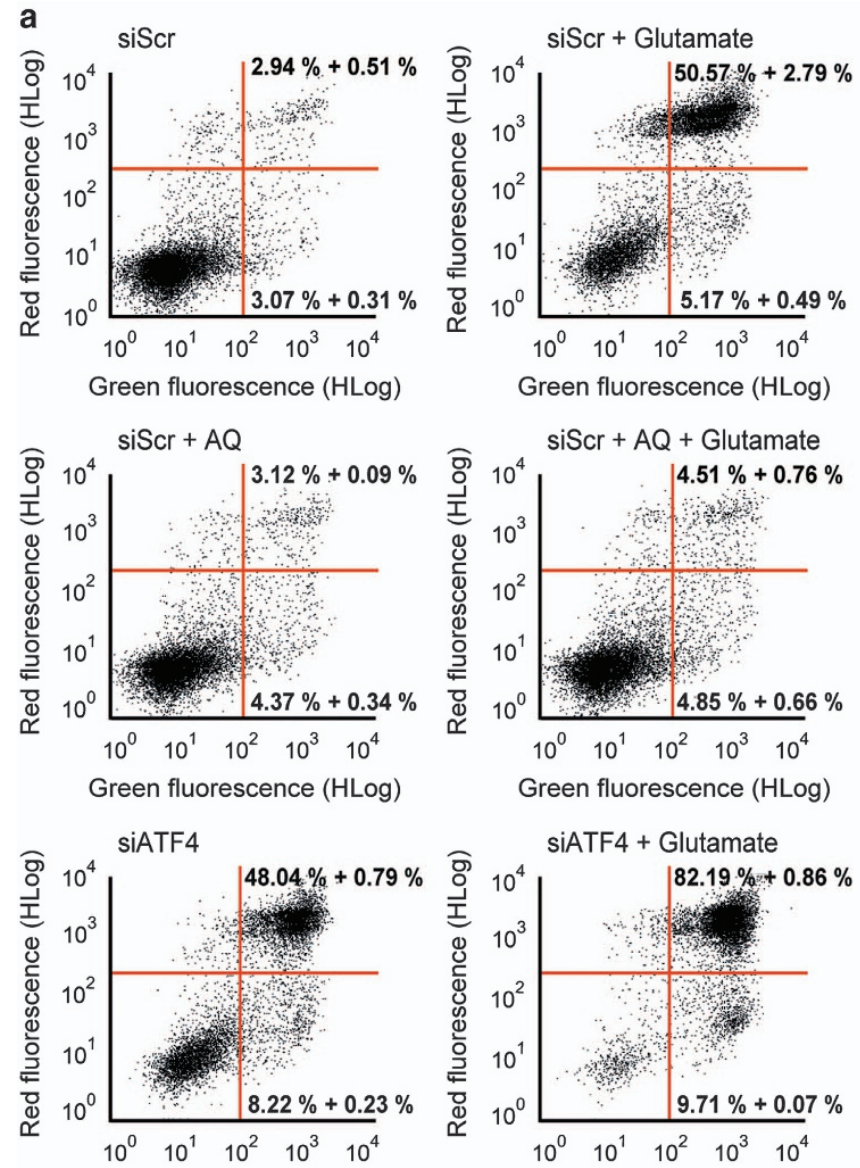

Green fluorescence (HLog)

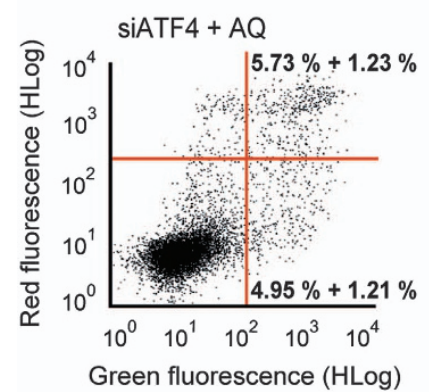

b
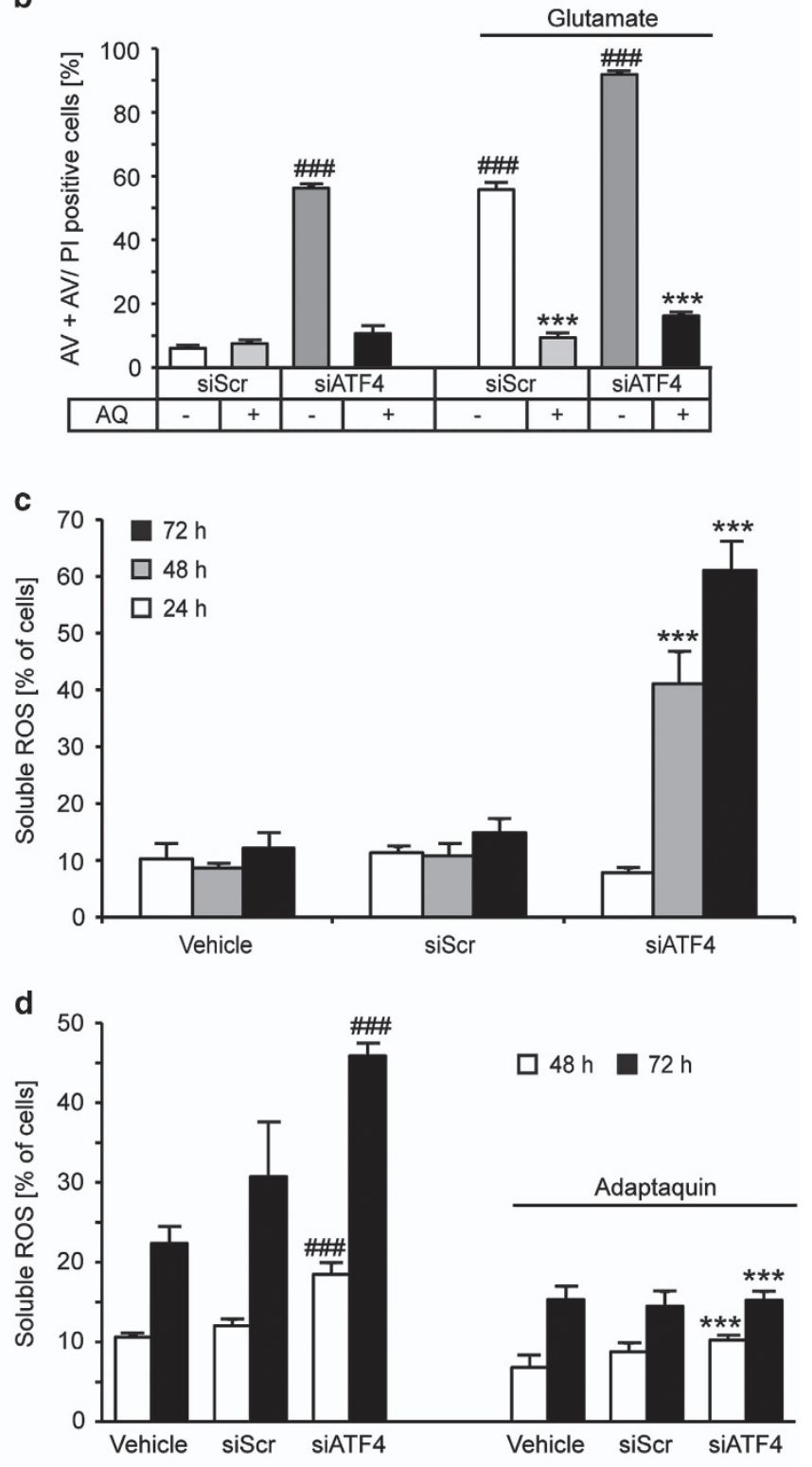

Figure 8 ATF4 silencing does not diminish AQ-mediated protection. (a) Representative dot plots show cell death after glutamate challenge $(6 \mathrm{mM}, 25 \mathrm{~h})$ analyzed by AV/PI staining and subsequent FACS analysis. (b) Quantification of AV- and AV/PI-positive cells from the plots in (a) $(n=3)$. Data are shown as mean \pm S.D. $\# \# \#<0.001$ compared with untreated siScr; ${ }^{\star \star *} P<0.001$ compared with glutamate-treated siScr (ANOVA, Scheffé's test). (c) Quantification of DCF staining reveals time-dependent formation of soluble ROS after ATF4 gene silencing. Data are shown as mean \pm S.D $(n=4) .{ }^{* *} P<0.001$ compared with respective vehicle. (d) Cotreatment with AQ prevents generation of soluble ROS after ATF4 knockdown revealed by DCF staining and subsequent FACS analysis. Data are given as mean \pm S.D. $(n=3)$. ${ }^{\# \# ~} P<0.001$ compared with respective untreated vehicle; ${ }^{* \star *} P<0.001$ compared with respective untreated siATF4

the pharmacological HIF-PHD inhibitors against glutamateinduced cell death. However, knockdown of PHD1 by CRISPR/Cas9 was just as effective inferring that PHD2 and PHD3 do not have a significant role during oxytosis. This assumption is in line with previous findings where knockdown of both isoforms did not abolish oxidative-stress-induced death in cortical neurons. ${ }^{14}$ In contrast, overexpression of PHD3 (but not PHD1 or PHD2) induces apoptosis in PC12 cells $^{53}$ and also enhanced the expression of SM-20, a rat orthologue of PHD3 that promotes cell death in PC12 cells ${ }^{54}$ and sympathetic neurons, ${ }^{55}$ indicating a proapoptotic function of PHD3.

PHD1 and PHD3 have been shown to regulate and interact with ATF4, ${ }^{40,41}$ a transcription factor displaying both antiapoptotic ${ }^{56,57}$ and proapoptotic properties, ${ }^{38,58}$ depending on the cellular system and experimental settings. According to observations of Köditz et al. ${ }^{41} \mathrm{DMOG}$ and siRNA-mediated PHD3 gene silencing stabilized ATF4 expression under 
normoxic conditions in HeLa cells. ${ }^{41}$ In the present study, AQmediated HIF-PHD inhibition restored ATF4 levels after the glutamate challenge. These data, together with the observed toxic effects of ATF4 downregulation, suggest an antiapoptotic function of ATF4 in HT-22 cells. This conclusion is in line with previous findings, where an overexpression of ATF4 protected against glutamate toxicity. ${ }^{42}$ In contrast to the present data, this protection was mediated by an ATF4-dependent upregulation of the $\mathrm{xCT}$ via the elF2 $a$ pathway and subsequent restoration of GSH levels. ${ }^{39} \mathrm{AQ}$ also maintained $\mathrm{xCT}$ levels after glutamate exposure. However, this neither correlated with the phosphorylation of elF2a nor restored GSH levels, suggesting that this pathway was not essential to mediate protection by $A Q$. In this study, AQ even protected ATF4silenced HT-22 cells from oxytosis and reduced the formation of soluble ROS generated by ATF4 downregulation. This corresponds with earlier results using ATF4 ${ }^{-/-}$cells cultured in the absence of reducing agents where DFO increased the survival, presumably because of the diminished formation of ROS. ${ }^{57}$ All in all, these data imply that, despite potential protective effects of ATF4, the regulation of this transcription factor was dispensable for $A Q$-mediated protection. Overall, transcriptional regulation by $A Q$ was unlikely the dominating mechanism of action in the present paradigm of oxytosis, as AQ-mediated protection even when applied $10 \mathrm{~h}$ after the onset of glutamate exposure.

In conclusion, the present study introduces inhibition of HIFPHDs as an eligible and promising target to abolish mitochondrial impairment and subsequent neuronal death. The current data suggest that both $A Q$ and selective PHD1 gene silencing act upstream of mitochondria. The mechanism by which $A Q$ prevents glutamate-induced oxidative stress includes multimodal regulations of enzymes involved in the regulation of oxidative stress that are independent of HIF-1a regulation.

\section{Materials and Methods}

Cell culture. HT-22 cells were cultured in Dulbecco's modified Eagle's medium with the addition of $10 \%$ heat-inactivated fetal calf serum, $100 \mathrm{U} / \mathrm{ml}$ penicillin, $100 \mathrm{mg} / \mathrm{ml}$ streptomycin and $2 \mathrm{mM}$ glutamine.

For inducing cell death, 3-7 mM glutamate or $600-800 \mu \mathrm{M} \mathrm{H}_{2} \mathrm{O}_{2}$ was added to the medium for the indicated amount of time.

SiRNA transfections were performed by using Lipofectamine RNAiMax (Invitrogen, Karlsruhe, Germany) following the manufacturer's protocol. After complex formation, an adequate number of cells was added in antibiotic-free medium to the transfection mix according to the following experimental procedure. Cells were treated after growing for $48 \mathrm{~h}$. The following siRNA sequences were used: $5^{\prime}$-AUCGAAGUCAAAC UCUUUCUU-3' (ATF4), 5'-CAGUGUGGCUGGCGGUCAU-3' (PHD1 siRNA II), 5'-GCCAUCACUGUCUGGUAUU-3' (PHD1 siRNA I), 5'-UAAUGUAUUGGAACGC AUA-3' (scrambled siRNA). AQ, DFO, DHB and CPO were dissolved in DMSO.

Generation of HT-22 cells with reduced PHD1 protein levels. WT HT-22 cells were seeded in 6-well plates at a density of 100000 cells/well, and after $24 \mathrm{~h}$, transfected with $5 \mu \mathrm{g}$ PHD1 CRISPR plasmid (U6gRNA-Cas9-2 A-GFP; MM0000478768, Sigma-Aldrich, Taufkirchen, Germany) using $4.5 \mu \mathrm{l}$ Attractene and up to $250 \mu \mathrm{l}$ OptiMEM/well. Two days later, transfection efficiency was confirmed by fluorescence microscopy and cells harvested with trypsin. Afterwards, cells were sorted via FACS and one, two or five cells seeded into a 96-well plate. To exclude dead cells, cells were costained with DAPI. Cells were cultured with weekly media change to obtain appropriate amount of cells for further analysis. Clone 2.17 was derived from initial seeding with two cells per well and clone 5.18 from five cells per well.
Cell viability. Cytotoxicity and cell viability were quantified by the MTT assay. After induction of cell death by glutamate for indicated time of treatment, MTT was added in a final concentration of $0.5 \mathrm{mg} / \mathrm{ml}$ to the culture medium. For calcium chelation experiments, the culture medium with or without extracellular calcium was prepared with indicated EGTA concentrations. In case of $\mathrm{H}_{2} \mathrm{O}_{2}$ treatment, the culture medium was removed after induction of cell death and replaced by PBS containing $0.5 \mathrm{mg} / \mathrm{ml} \mathrm{MTT}$. Cells were incubated for $1 \mathrm{~h}$ at $37^{\circ} \mathrm{C}$. The resulting purple formazan was dissolved in an appropriate amount of DMSO and absorbance measured at 570 versus $630 \mathrm{~nm}$ with FluoStar (BMG Labtech, Ortenberg, Germany).

For real-time measurement of cell viability, the XCELLigence system was used as described previously. ${ }^{59}$

Additionally, cell viability after ATF4 gene silencing was detected by an Annexin V/propidium iodide (AV/PI) staining using an Annexin-V-FITC Detection Kit (Promokine, Heidelberg, Germany) followed by FACS analysis. Annexin-V-FITC was excited at $488 \mathrm{~nm}$ and emission was detected through a 525/30 bandpass filter. Propidium iodide was excited at $488 \mathrm{~nm}$ and fluorescence emission was detected using a 690/50 bandpass filter. Data were collected from 10000 cells from at least three wells per condition.

RT-PCR. Forty-eight hours after siRNA transfection, total RNA amount was extracted by InviTrap Spin Universal RNA Kit (Stratec Molecular, Berlin, Germany). RT-PCR was performed with SuperScript III One-Step RT-PCR Kit with Platinum Taq (Invitrogen). The following primers were used: PHD1: forward, $5^{\prime}$-TTGCCTGGGTAG AAGGTCAC-3' and reverse, 5'-GCTCGATGTTGGCTACCACT-3'; PHD2: forward, 5'-AGCCATGGTTGCTTGTTACC-3' and reverse, 5'-CTCGCTCATCTGCATCAAAA-3'; GAPDH (glyceraldehyde 3-phosphate dehydrogenase): forward, 5'-AGGCCGGTG CTGAGTAT-3' and reverse, 5'-TGCCTGCTTCACCACCTTCT-3'. DNA products were visualized on a $1 \%$ agarose gel by UV illumination.

Protein analysis and western blot. Forty-eight hours after siRNA transfection or after the indicated time of glutamate challenge, cells were washed once with PBS and lysed with buffer containing $0.25 \mathrm{M}$ mannitol, $0.05 \mathrm{M}$ Tris, $1 \mathrm{M}$ EDTA, 1 M EGTA, $1 \mathrm{mM}$ DTT, 1\% Triton-X, supplemented with Complete Mini Protease Inhibitor Cocktail and PhosSTOP (both Roche Diagnostics, Penzberg, Germany). Extracts were centrifuged at $10000 \mathrm{xg}$ for $15 \mathrm{~min}$ at $4{ }^{\circ} \mathrm{C}$ to eliminate insoluble fragments. The total amount of protein was determined by Pierce BCA Protein Assay Kit (Perbio Science, Bonn, Germany). For western blot analysis, 40-60 $\mu \mathrm{g}$ of protein were loaded on a $12.5 \%$ SDS gel and blotted onto a PVDF membrane at $20 \mathrm{~mA}$ for $21 \mathrm{~h}$. Incubation with primary antibody was performed overnight at $4{ }^{\circ} \mathrm{C}$. The following primary antibodies were used: anti-PHD1 (Novus Biologicals, Littleton, CO, USA) $1: 1000$ in $0.5 \%$ IBLOCK, anti-superoxide dismutase 2 (Novus Biologicals) 1:1000 in 5\% skim milk, anti-ATF4 (Santa Cruz Biotechnology, Santa Cruz, CA, USA) 1:500 in 0.5\% IBLOCK, anti-xCT (Abcam, Cambridge, UK) 1:1 000 in 5\% BSA, anti-elF2 $\alpha$ (Cell Signaling, Danvers, MA, USA) 1:1 000 in 5\% BSA, anti-phospho-elF2 $\alpha$ (Cell Signaling) 1:500 in 5\% BSA, anti-15LOX 1 1:500 in 0.5\% IBLOCK (Abcam) and anti-actin C4 (MB Biomedicals, Illkirch, France) $1: 10000$ in $5 \%$ skim milk. After incubation with proper secondary HRPlabeled antibody (Vector Laboratories, Burlingame, CA, USA), western blot signals were detected by chemiluminescence with Chemidoc software (Bio-Rad, Munich, Germany) and quantified with the Quantity One software (Bio-Rad).

Mitochondrial ROS formation. Formation of mitochondrial ROS was investigated via MitoSOX red staining (Invitrogen), which shows increasing red fluorescence upon reaction with mitochondrial ROS. For analysis of PHD inhibitors, HT-22 cells were seeded in 24-well plates with 55000 cells per well. For functional analysis of PHD1 siRNAs, cells were transfected with 22000 cells per well and grown for $48 \mathrm{~h}$ before treatment. At indicated time points after onset of treatment, cells were stained with MitoSOX red for $30 \mathrm{~min}$ at $37^{\circ} \mathrm{C}$ at a final concentration of $2.5 \mu \mathrm{M}$. After collecting and washing once with PBS, cells were resuspended in an appropriate amount of PBS and red fluorescence was detected by FACS analysis. MitoSOX red was excited at $488 \mathrm{~nm}$ and emission was recorded using a 690/50 bandpass filter. Data were collected from 10000 cells from at least three wells per condition.

Mitochondrial membrane potential. For the analysis of changes in the MMP after glutamate exposure, the MitoPT $\Delta \Psi m$ Kit (Immunochemistry Technologies, Hamburg, Germany) was used. For the analysis of HIF-PHD inhibitors, HT-22 cells were seeded in 24-well plates with 55000 cells per well. For functional analysis of PHD1 siRNAs, cells were transfected with 22000 cells per 
well and grown for $48 \mathrm{~h}$ before treatment. After glutamate challenge, in particular, HIF-PHD inhibition cells were collected and stained with TMRE in a final concentration of $200 \mathrm{nM}$ for $20 \mathrm{~min}$ at $37^{\circ} \mathrm{C}$. After washing with PBS, cells were resuspended in an appropriate amount of assay buffer and TMRE fluorescence was assessed via FACS analysis. TMRE was excited at $488 \mathrm{~nm}$ and emission was recorded using a 690/50 bandpass filter. Data were collected from 10000 cells from at least three wells per condition.

Lipid peroxidation. For detection of lipid peroxidation in case of HIF-PHD inhibition, HT-22 cells were seeded in 24-well plates with 55000 cells per well. To analyze the effects of PHD1 silencing, cells were transfected with PHD1 siRNA with 22000 cells per well and grown for $48 \mathrm{~h}$. After treatment with glutamate, cells were stained with BODIPY $581 / 591 \mathrm{C}_{11}$ (Invitrogen) for $1 \mathrm{~h}$ at $37^{\circ} \mathrm{C}$ in a culture medium at a final concentration of $2 \mu \mathrm{M}$. After collecting and washing once with PBS, cells were resuspended in an appropriate amount of PBS. Lipid peroxidation was analyzed by detection of fluorescence shift from green to red via FACS analysis. Excitation was performed at $488 \mathrm{~nm}$ and emission was recorded with a 525/30 bandpass filter (green) and a 690/50 bandpass filter (red). Data were collected from 10000 cells from at least three wells per condition.

Intracellular soluble ROS. For the analysis of intracellular soluble ROS, cells were seeded in 24-well plates with 55000 cells per well and treated with glutamate and $A Q$ or transfected with ATF4 siRNA for the indicated amount of time. To analyze the effects of $A Q$ on the formation of soluble ROS in ATF4-silenced cells, $A Q$ was added immediately after transfection to the culture medium. For detection of intracellular soluble ROS, the culture medium was replaced by a medium without serum containing $\mathrm{CM}-\mathrm{H}_{2}$ DCFDA in a final concentration of $2.5 \mu \mathrm{M}$. Cells were incubated at $37^{\circ} \mathrm{C}$ for $30 \mathrm{~min}$ followed by 30 min incubation without dye in serum containing fresh medium. Subsequently, cells were harvested and washed once with PBS. For detection of green fluorescence, cells were resuspended in a suitable amount of PBS and analyzed by FACS. DCF was excited at $488 \mathrm{~nm}$ and emission was recorded with a 525/30 bandpass filter. Data were collected from 10000 cells from at least three wells per condition.

ATP measurements. For analysis of total ATP levels, cells were seeded in white 96 -well plates (8 000 cells per well) and treated with HIF-PHD inhibitors or transfected with PHD1 siRNA (3500 cells per well) and grown for $48 \mathrm{~h}$. At indicated time points of glutamate exposure, ATP levels were analyzed by luminescence detection with FluoStar according to the manufacturer's protocol using the ViaLight plus Kit (Lonza, Verviers, Belgium).

Measurement of cellular OCR. To determine the cellular OCR, cells were plated in XF96-well microplates (8000 cells per well; Seahorse Bioscience, Copenhagen, Denmark) and treated with HIF-PHD inhibitors and glutamate. After appropriate time, OCR measurements were performed as described previously ${ }^{60}$ with minor modifications. Briefly, the growth medium was washed off and replaced by $\sim 180 \mu \mathrm{l}$ of assay medium (with $4.5 \mathrm{~g} / \mathrm{l}$ glucose as the sugar source, $2 \mathrm{mM}$ glutamine, $1 \mathrm{mM}$ pyruvate, $\mathrm{pH} 7.35$ ) and cells were incubated at $37^{\circ} \mathrm{C}$ for $60 \mathrm{~min}$. Three baseline measurements were recorded before adding the compounds. Oligomycin was injected in port A $(20 \mu \mathrm{l})$ at a final concentration of $3 \mu \mathrm{M}, \mathrm{FCCP}$ (22.5 $\mu \mathrm{l}$ in port B) at a concentration of $0.4 \mu \mathrm{M}$ and rotenone/antimycin $\mathrm{A}$ ( $25 \mu \mathrm{l}$ in port C) at a concentration of $1 \mu \mathrm{M}$. Three measurements were performed after the addition of each compound ( 4 min mixing followed by 3 min measuring).

GSH measurement. To determine GSH levels, HT-22 cells were seeded in 6-well plates (180 000 cells per well). After treatment with glutamate and $A Q$ for indicated amount of time, two wells per condition were harvested by scratching and washed once with PBS. GSH measurements were performed using GSH Assay Kit (Cayman Chemical Company, Ann Arbor, MI, USA) following the manufacturer's protocol. Briefly, cells were resuspended in MES buffer (0.4 M 2-( $N$-mopholino) ethanesulfonic acid, $0.1 \mathrm{M}$ phosphate, $2 \mathrm{mM}$ EDTA, pH 6.0) and homogenized by sonification. Insoluble fragments were removed by centrifugation at $10000 \mathrm{xg}$ for $15 \mathrm{~min}$. The supernatant was deproteinated by the addition of an equal volume of metaphosphoric acid $(1.25 \mathrm{M})$. After incubation for $5 \mathrm{~min}$, the mixture was centrifuged at $17000 \mathrm{xg}$ for $10 \mathrm{~min}$. Subsequently, the supernatant was mixed with a $4 \mathrm{M}$ solution of triethanolamine to increase the $\mathrm{pH}$. After transferring into a 96-well plate, the assay cocktail containing provided MES buffer, cofactor mixture, enzyme mixture and Ellman's reagent was added. Absorbance was measured at $405 \mathrm{~nm}$ after 30 min of incubation. Total GSH amount was determined via standard curve calculation and normalized to protein content.

Statistical analysis. All data are given as mean \pm S.D. Statistical comparison between treatment groups was performed by analysis of variance (ANOVA) followed by Scheffé's post hoc test. Calculations were executed with Winstat standard statistical software (R Fitch Software, Bad Krozingen, Germany).

\section{Conflict of Interest}

The authors declare no conflict of interest.

Acknowledgements. We thank the excellent technical support by Katharina Elsässer and Eileen Daube. Moreover, we thank Emma Esser for careful editing of the manuscript. Part of this work was supported by the DFG FOR 2107 and the vonBehring-Röntgen Foundation.

\section{Author contributions}

$\mathrm{SN}$ and $\mathrm{CC}$ conceived and designed the experiments. SN and $\mathrm{AD}$ performed the experiments. SN, RR, SK, IA and CC wrote the manuscript.

1. Lin MT, Beal MF. Mitochondrial dysfunction and oxidative stress in neurodegenerative diseases. Nature 2006; 443: 787-795.

2. Culmsee $C$, Krieglstein J. Ischaemic brain damage after stroke: new insights into efficient therapeutic strategies. EMBO Rep 2007; 8: 129-133.

3. Culmsee $\mathrm{C}$, Landshamer $\mathrm{S}$. Molecular insights into mechanisms of the cell death program: role in the progression of neurodegenerative disorders. Curr Alzheimer Res 2006; 3: 269-283.

4. Mattson MP. Apoptosis in neurodegenerative disorders. Nat Rev Mol Cell Biol 2000; 1 : 120-129.

5. Pallast S, Arai K, Wang X, Lo EH, van Leyen K. 12/15-Lipoxygenase targets neuronal mitochondria under oxidative stress. J. Neurochem 2009; 111: 882-889.

6. Galluzzi L, Bravo-San Pedro JM, Vitale I, Aaronson SA, Abrams JM, Adam D et al. Essential versus accessory aspects of cell death: recommendations of the NCCD 2015. Cell Death Differ 2015; 22: 58-73.

7. Orrenius $\mathrm{S}$, Nicotera $\mathrm{P}$, Zhivotovsky B. Cell death mechanisms and their implications in toxicology. Toxicol Sci 2011; 119: 3-19.

8. Fleury C, Mignotte B, Vayssière J-L. Mitochondrial reactive oxygen species in cell death signaling. Biochimie 2002; 84: 131-141.

9. Landshamer S, Hoehn M, Barth N, Duvezin-Caubet S, Schwake G, Tobaben S et al. Bid-induced release of AIF from mitochondria causes immediate neuronal cell death. Cell Death Differ 2008; 15: 1553-1563.

10. Galluzzi L, Blomgren K, Kroemer G. Mitochondrial membrane permeabilization in neuronal injury. Nat Rev Neurosci 2009; 10: 481-494.

11. Niatsetskaya Z, Basso M, Speer RE, McConoughey SJ, Coppola G, Ma TC et al. HIF prolyl hydroxylase inhibitors prevent neuronal death induced by mitochondrial toxins: therapeutic implications for Huntington's disease and Alzheimer's disease. Antioxid Redox Signal 2010; 12: 435-443.

12. Aragonés J, Schneider M, Van Geyte K, FraisI P, Dresselaers T, Mazzone M et al. Deficiency or inhibition of oxygen sensor Phd1 induces hypoxia tolerance by reprogramming basal metabolism. Nat Genet 2008; 40: 170-180.

13. Siddiq A, Aminova LR, Ratan RR. Hypoxia inducible factor prolyl 4-hydroxylase enzymes: center stage in the battle against hypoxia, metabolic compromise and oxidative stress. Neurochem Res 2007; 32: 931-946.

14. Siddiq A, Aminova LR, Troy CM, Suh K, Messer Z, Semenza GL et al. Selective inhibition of hypoxia-inducible factor (HIF) prolyl-hydroxylase 1 mediates neuroprotection against normoxic oxidative death via HIF- and CREB-independent pathways. J Neurosci 2009; 29: 8828-8838.

15. Xie L, Xiao K, Whalen EJ, Forrester MT, Freeman RS, Fong G et al. Oxygen-regulated beta (2)-adrenergic receptor hydroxylation by EGLN3 and ubiquitylation by pVHL. Sci Signal 2009; 2: ra33.

16. Mikhaylova O, Ignacak ML, Barankiewicz TJ, Harbaugh SV, Yi Y, Maxwell PH et al. The von Hippel-Lindau tumor suppressor protein and Egl-9-Type proline hydroxylases regulate the large subunit of RNA polymerase II in response to oxidative stress. Mol Cell Biol 2008; 28: 2701-2717.

17. Zhang Q, Gu J, Li L, Liu J, Luo B, Cheung HW et al. Control of cyclin D1 and breast tumorigenesis by the EgIN2 prolyl hydroxylase. Cancer Cell 2009; 16: 413-424.

18. Chen RL, Nagel S, Papadakis M, Bishop T, Pollard P, Ratcliffe PJ et al. Roles of individual prolyl-4-hydroxylase isoforms in the first 24 hours following transient focal cerebral ischaemia: insights from genetically modified mice. J Physiol 2012; 590: 4079-4091.

19. Kunze R, Zhou W, Veltkamp R, Wielockx B, Breier G, Marti HH. Neuron-specific prolyl-4hydroxylase domain 2 knockout reduces brain injury after transient cerebral ischemia. Stroke 2012; 43: 2748-2756. 
20. Siddiq A, Ayoub IA, Chavez JC, Aminova L, Shah S, LaManna JC et al. Hypoxia-inducible factor prolyl 4-hydroxylase inhibition. A target for neuroprotection in the central nervous system. J Biol Chem 2005; 280: 41732-41743.

21. Nagel S, Papadakis M, Chen R, Hoyte LC, Brooks KJ, Gallichan D et al. Neuroprotection by dimethyloxalylglycine following permanent and transient focal cerebral ischemia in rats. J Cereb Blood Flow Metab 2011; 31: 132-143.

22. Ogle ME, Gu X, Espinera AR, Wei L. Inhibition of prolyl hydroxylases by dimethyloxaloylglycine after stroke reduces ischemic brain injury and requires hypoxia inducible factor-1 $\alpha$. Neurobiol Dis 2012; 45: 733-742.

23. Ritchie CW, Bush Al, Mackinnon A, Macfarlane S, Mastwyk M, MacGregor L et al. Metalprotein attenuation with iodochlorhydroxyquin (clioquinol) targeting Abeta amyloid deposition and toxicity in Alzheimer disease: a pilot phase 2 clinical trial. Archiv Neurol 2003; 60: 1685-1691.

24. Wu Y, Li X, Xie W, Jankovic J, Le W, Pan T. Neuroprotection of deferoxamine on rotenoneinduced injury via accumulation of HIF-1 alpha and induction of autophagy in SH-SY5Y cells. Neurochem Int 2010; 57: 198-205.

25. Chinta SJ, Rajagopalan S, Ganesan A, Andersen JK. A possible novel anti-inflammatory mechanism for the pharmacological prolyl hydroxylase inhibitor 3,4-dihydroxybenzoate: implications for use as a therapeutic for Parkinson's disease. Parkinson's Dis 2012; 2012: 364684.

26. Lee DW, Rajagopalan S, Siddiq A, Gwiazda R, Yang L, Beal MF et al. Inhibition of prolyl hydroxylase protects against 1-methyl-4-phenyl-1,2,3,6-tetrahydropyridine-induced neurotoxicity: model for the potential involvement of the hypoxia-inducible factor pathway in Parkinson disease. J Biol Chem 2009; 284: 29065-29076.

27. Smirnova NA, Rakhman I, Moroz N, Basso M, Payappilly J, Kazakov S et al. Utilization of an in vivo reporter for high throughput identification of branched small molecule regulators of hypoxic adaptation. Chem Biol 2010; 17: 380-391.

28. Fukui M, Zhu BT. Mitochondrial superoxide dismutase SOD2, but not cytosolic SOD1, plays a critical role in protection against glutamate-induced oxidative stress and cell death in HT22 neuronal cells. Free Radic Biol Med 2010; 48: 821-830.

29. Tan S, Schubert D, Maher P. Oxytosis: a novel form of programmed cell death. Curr Top Med Chem 2001; 1: 497-506.

30. Tobaben S, Grohm J, Seiler A, Conrad M, Plesnila N, Culmsee C. Bid-mediated mitochondrial damage is a key mechanism in glutamate-induced oxidative stress and AlF-dependent cell death in immortalized HT-22 hippocampal neurons. Cell Death Differ 2011; 18: 282-292.

31. Grohm J, Plesnila N, Culmsee C. Bid mediates fission, membrane permeabilization and peri-nuclear accumulation of mitochondria as a prerequisite for oxidative neuronal cell death. Brain Behav Immun 2010; 24: 831-838.

32. Neitemeier S, Ganjam GK, Diemert S, Culmsee C. Pifithrin- $\alpha$ provides neuroprotective effects at the level of mitochondria independently of p53 inhibition. Apoptosis 2014; 19: 1665-1677.

33. Reuther C, Ganjam GK, Dolga AM, Culmsee C. The serine protease inhibitor TLCK attenuates intrinsic death pathways in neurons upstream of mitochondrial demise. Apoptosis 2014; 19: 1545-1558.

34. Tan S, Sagara Y, Liu Y, Maher P, Schubert D. The regulation of reactive oxygen species production during programmed cell death. J. Cell Biol. 1998; 141: 1423-1432.

35. Green DR, Galluzzi L, Kroemer G. Cell biology. Metabolic control of cell death. Science (New York, NY) 2014; 345: 1250256.

36. Dringen R, Hirrlinger J. Glutathione pathways in the brain. Biol Chem 2003; 384: 505-516.

37. Li Z, Shi K, Guan L, Cao T, Jiang Q, Yang Y et al. ROS leads to MnSOD upregulation through ERK2 translocation and p53 activation in selenite-induced apoptosis of NB4 cells. FEBS Lett 2010; 584: 2291-2297.

38. Lange PS, Chavez JC, Pinto JT, Coppola G, Sun CW, Townes TM et al. ATF4 is an oxidative stress-inducible, prodeath transcription factor in neurons in vitro and in vivo. J Exp Med 2008; 205: 1227-1242.

39. Lewerenz J, Sato H, Albrecht P, Henke N, Noack R, Methner A et al. Mutation of ATF4 mediates resistance of neuronal cell lines against oxidative stress by inducing $\mathrm{xCT}$ expression. Cell Death Differ 2011; 19: 847-858.

40. Hiwatashi Y, Kanno K, Takasaki C, Goryo K, Sato T, Torii S et al. PHD1 interacts with ATF4 and negatively regulates its transcriptional activity without prolyl hydroxylation. Exp Cell Res 2011; 317: 2789-2799.

41. Köditz J, Nesper J, Wottawa M, Stiehl DP, Camenisch G, Franke $C$ et al. Oxygen-dependent ATF-4 stability is mediated by the PHD3 oxygen sensor. Blood 2007; 110: 3610-3617.

42. Lewerenz J, Maher P. Basal Levels of elF2 phosphorylation determine cellular antioxidant status by regulating ATF4 and xCT expression. J Biol Chem 2009; 284: 1106-1115.
43. Zaman $\mathrm{K}$, Ryu $\mathrm{H}$, Hall D, O'Donovan $\mathrm{K}$, Lin Kl, Miller MP et al. Protection from oxidative stress-induced apoptosis in cortical neuronal cultures by iron chelators is associated with enhanced DNA binding of hypoxia-inducible factor-1 and ATF-1/CREB and increased expression of glycolytic enzymes, p21(waf1/cip1), and erythropoietin. J Neurosci 1999; 19: 9821-9830.

44. Li D, Bai T, Brorson JR. Adaptation to moderate hypoxia protects cortical neurons against ischemia-reperfusion injury and excitotoxicity independently of HIF-1 $\alpha$. Exp Neurol 2011 230: 302-310.

45. Durán RV, MacKenzie ED, Boulahbel H, Frezza C, Heiserich L, Tardito $\mathrm{S}$ et al. HIF-independent role of prolyl hydroxylases in the cellular response to amino acids. Oncogene 2013; 32: 4549-4556.

46. Berra E, Benizri E, Ginouvès A, Volmat V, Roux D, Pouysségur J. HIF prolyl-hydroxylase 2 is the key oxygen sensor setting low steady-state levels of HIF-1alpha in normoxia. EMBO J 2003; 22: 4082-4090

47. Zhang J, Cao Q, Li S, Lu X, Zhao Y, Guan JS et al. 3-Hydroxybutyrate methyl ester as a potential drug against Alzheimer's disease via mitochondria protection mechanism. Biomaterials 2013; 34: 7552-7562.

48. Lau Y-S, Patki G, Das-Panja K, Le W-D, Ahmad SO. Neuroprotective effects and mechanisms of exercise in a chronic mouse model of Parkinson's disease with moderate neurodegeneration. Eur J Neurosci 2011; 33: 1264-1274.

49. Marques-Aleixo I, Oliveira PJ, Moreira PI, Magalhães J, Ascensão A. Physical exercise as a possible strategy for brain protection: evidence from mitochondrial-mediated mechanisms. Prog Neurobiol 2012; 99: 149-162.

50. Suh H-W, Kang S, Kwon K-S. Curcumin attenuates glutamate-induced HT22 cell death by suppressing MAP kinase signaling. Mol Cell Biochem 2007; 298: 187-194.

51. Karuppagounder SS, Ratan RR. Hypoxia-inducible factor prolyl hydroxylase inhibition: robust new target or another big bust for stroke therapeutics? J Cereb Blood Flow Metab 2012; 32: 1347-1361

52. Quaegebeur A, Segura I, Schmieder R, Verdegem D, Decimo I, Bifari F et al. Deletion or inhibition of the oxygen sensor PHD1 protects against ischemic stroke via reprogramming of neuronal metabolism. Cell Metab 2016; 23: 280-291.

53. Lee $\mathrm{S}$ et al. Neuronal apoptosis linked to EglN3 prolyl hydroxylase and familial pheochromocytoma genes: developmental culling and cancer. Cancer Cell 2005; 8: 155-167.

54. Straub JA, Lipscomb EA, Yoshida ES, Freeman RS. Induction of SM-20 in PC12 cells leads to increased cytochrome $c$ levels, accumulation of cytochrome $c$ in the cytosol, and caspasedependent cell death. J Neurochem 2003; 85: 318-328.

55. Lipscomb EA, Sarmiere PD, Freeman RS. SM-20 is a novel mitochondrial protein that causes caspase-dependent cell death in nerve growth factor-dependent neurons. J Biol Chem 2001; 276: 5085-5092.

56. Masuoka HC, Townes TM. Targeted disruption of the activating transcription factor 4 gene results in severe fetal anemia in mice. Blood 2002; 99: 736-745.

57. Harding HP, Zhang Y, Zeng H, Novoa I, Lu PD, Calfon M et al. An integrated stress response regulates amino acid metabolism and resistance to oxidative stress. Mol Cell 2003; 11 619-633.

58. Ord D, Meerits K, Ord T. TRB3 protects cells against the growth inhibitory and cytotoxic effect of ATF4. Exp Cell Res 2007; 313: 3556-3567.

59. Diemert S, Dolga AM, Tobaben S, Grohm J, Pfeifer S, Oexler E et al. Impedance measurement for real time detection of neuronal cell death. J Neurosci Methods 2012; 203: 69-77.

60. Gohil VM, Sheth SA, Nilsson R, Wojtovich AP, Lee JH, Perocchi F et al. Nutrient-sensitized screening for drugs that shift energy metabolism from mitochondrial respiration to glycolysis. Nat Biotechnol 2010; 28: 249-255.

Cell Death and Disease is an open-access journal published by Nature Publishing Group. This work is licensed under a Creative Commons Attribution 4.0 International License. The images or other third party material in this article are included in the article's Creative Commons license, unless indicated otherwise in the credit line; if the material is not included under the Creative Commons license, users will need to obtain permission from the license holder to reproduce the material. To view a copy of this license, visit http://creativecommons.org/licenses/by/4.0/

\section{Supplementary Information accompanies this paper on Cell Death and Disease website (http://www.nature.com/cddis)}

